Old Dominion University

ODU Digital Commons

OEAS Faculty Publications

Ocean, Earth \& Atmospheric Sciences

2003

\title{
A Biooptical Model of Irradiance Distribution and Photosynthesis in Seagrass Canopies
}

Richard C.Zimmerman

Old Dominion University, rzimmerm@odu.edu

Follow this and additional works at: https://digitalcommons.odu.edu/oeas_fac_pubs

Part of the Environmental Monitoring Commons, Marine Biology Commons, and the Oceanography Commons

\section{Repository Citation}

Zimmerman, Richard C., "A Biooptical Model of Irradiance Distribution and Photosynthesis in Seagrass Canopies" (2003). OEAS Faculty Publications. 120.

https://digitalcommons.odu.edu/oeas_fac_pubs/120

\section{Original Publication Citation}

Zimmerman, R.C. (2003). A biooptical model of irradiance distribution and photosynthesis in seagrass canopies. Limnology and Oceanography, 48(1), 568-585. doi: 10.4319/lo.2003.48.1_part_2.0568

This Article is brought to you for free and open access by the Ocean, Earth \& Atmospheric Sciences at ODU Digital Commons. It has been accepted for inclusion in OEAS Faculty Publications by an authorized administrator of ODU Digital Commons. For more information, please contact

digitalcommons@odu.edu. 


\title{
A biooptical model of irradiance distribution and photosynthesis in seagrass canopies
}

\author{
Richard C. Zimmerman ${ }^{1}$
}

Moss Landing Marine Laboratories, California State University, 8272 Moss Landing Road, Moss Landing, California 95039

\begin{abstract}
Although extremely vulnerable to coastal eutrophication, seagrasses represent important structuring elements and sources of primary production in shallow waters. They also generate an optical signature that can be tracked remotely. Accurate knowledge of light absorption and scattering by submerged plant canopies permits the calculation of important plant- and ecosystem-level properties, including rates of photosynthesis, vegetation abundance, and distribution. The objectives of this study were to develop a realistic, yet simply parameterized two-flow model of plane irradiance distribution through a seagrass canopy submerged in an optically active water column, to evaluate its performance against in situ measurements, and to explore the impacts of variations in canopy architecture on irradiance distribution and photosynthesis within the canopy. Allometric functions derived from leaf length-frequency data enabled simple parameterization of canopy architecture. Model predictions of downwelling spectral irradiance distributions in seagrass canopies growing in both oligotrophic and eutrophic waters were within $15 \%$ of field measurements. Thus, the model provides a robust tool for investigating photosynthetic performance of seagrass canopies as functions of water quality, depth distribution, canopy architecture, and leaf orientation. Model predictions of upwelling irradiance were less reliable, particularly in the upper half of the canopies. The model was more sensitive to leaf orientation than leaf optical properties, seabed reflectance, or the average cosine of downwelling irradiance. Better knowledge of leaf orientation appears to be a fruitful avenue for improving our understanding of the interaction between seagrasses and the submarine light environment.
\end{abstract}

The distribution of radiant energy in plant canopies determines one of the fundamental interactions of biophysical ecology - that of energy exchange between photosynthetic organisms and their environment. Accurate knowledge of light absorption by plant canopies permits the calculation of important plant- and ecosystem-level properties, including rates of primary production and, in the case of terrestrial plants, evapotranspiration (Nobel 1991; Campbell and Norman 1998). Knowledge of light scattering by plant canopies is crucial for remote sensing quantification of vegetation abundance and distribution, as well as for the development of inversion techniques to infer plant chemical composition important for ecosystem-scale estimates of plant growth and

${ }^{1}$ Corresponding author (rzimmer197@aol.com).

\section{Acknowledgments}

Many thanks to all CoBOP participants for generous collaboration, assistance with fieldwork and warm camaraderie during five field campaigns to Lee Stocking Island. Special thanks to D. Kohrs, M. Cummings, S. Wittlinger, and S. Palacios for assistance with laboratory and field measures of seagrass density, leaf dimensions, and optical properties, and numerous discussions and suggestions that improved both the model and manuscript. E. Louchard and P. Reid provided carbonate sediment reflectance spectra; E. Boss and R. Zaneveld provided water column optical properties from Lee Stocking Island. J. Norris shared eelgrass morphometrics from Dumas Bay, Washington, collected under the auspices of the Washington State Department of Natural Resources. R. Maffione provided Hydrolight simulations used to parameterize water column variables. R. Maffione, C. Mobley, H. Dierssen, and L. Drake also provided important discussions and suggestions for improving both the model and the manuscript. A. Morel and two anonymous reviewers provided extensive, thoughtful comments that greatly improved the final product. Financial support was provided by the Environmental Optics program, Office of Naval Research, as part of the CoBOP DRI (award No. N00014-97-1-0032). biogeochemical flux (Jacquemoud et al. 1996; LaCapra et al. 1996; Broge and Leblanc 2000).

Seagrass meadows represent an important structuring element and major source of primary production in shallow waters worldwide (Hemminga and Duarte 2000). They also provide a strong optical signature that can be tracked using satellite and airborne remote sensing (Armstrong 1993; Mumby et al. 1997; Chauvaud et al. 2001; Dierssen et al. 2003). Despite the high productivity of seagrass meadows, these marine angiosperms are vulnerable to the light-limiting effects of sediment loading and coastal eutrophication (Orth 1977; Cambridge and McComb 1984; Zimmerman et al. 1991; Tomasko and Lapointe 1994; Zimmerman et al. 1995). Limited understanding of many processes crucial to seagrass production often necessitates the development of semiempirical relationships with limited applicability to other species or locations. Consequently, models of light-limited seagrass productivity have been constructed using a variety of assumptions and different levels of mechanistic detail (e.g., Short 1980; Wetzel and Neckles 1986; Burd and Dunton 2001). Self-shading, which ultimately regulates the density of any plant canopy, has been incorporated into seagrass production models through a simple light attenuation coefficient derived by correlation from canopy height and shoot density (Short 1980). It has also been incorporated as an explicit feedback term affecting photosynthesis but without a direct link to the submarine light environment (Burd and Dunton 2001). Both approaches can provide useful predictions of seagrass productivity when there are sufficient data for accurate least-squares parameterization of the transfer coefficients for a particular population or environment. These models, however, are not easily generalized to other populations or situations without recalibration, which requires extensive collection of new data. Further, the formulations do 
not separate the effects of water column attenuation from those of the canopy. This hinders their utility for developing general water-quality criteria to manage submarine light environments with respect to submerged aquatic vegetation in heterogeneous and temporally variable coastal waters. Finally, they do not address the canopy-leaving irradiance, which is necessary for remote sensing of seagrass meadows.

Radiative transfer theory provides a robust framework to develop more mechanistic models of the submarine light environment, system-level productivity, and remotely sensed reflectance of seagrass meadows in optically shallow waters. Exact solutions to the radiance transfer equations have been developed for natural waters in which the optical medium is a continuous material composed of randomly arranged scattering elements separated by large distances relative to the wavelength of light (Mobley 1994). Plant leaves, however, represent a dense packaging of optically active material, which violates the single-scattering assumptions of these exact solutions. Consequently, models of irradiance distribution in plant canopies must rely on more empirical relationships between leaf optical properties and light attenuation by the bulk canopy (Goudriaan 1988; Shultis and Myneni 1988; Ganapol and Myneni 1992).

Although less elegant mathematically, the simulation of irradiance transfer by the use of two-flow equations provides a simple, quasimechanistic framework for understanding the relationship between water column optical properties, submerged plant canopies, and irradiance distribution in shallow waters. Ackleson and Klemas (1986) developed a two-flow model to calculate the submarine light field within a twolayered system composed of a homogeneous water column bounded below by a vertically homogeneous seagrass canopy. Zimmerman and Mobley (1997) extended that approach with a vertically layered model of downwelling irradiance distribution in seagrass canopies but ignored water column effects within the canopy and modeled the leaves as scalar irradiance collectors. The goals of this study were (i) to develop a more realistic, yet simply parameterized model of plane irradiance distribution through a vertically defined leaf canopy submerged in an optically active water column, (ii) to evaluate its performance against in situ measurements, and (iii) to explore the impacts of variations in canopy architecture on irradiance distribution and photosynthesis. Mechanistic characterization of the details of light absorption by vertically differentiated plant canopies helps to understand the environmental regulation of seagrass productivity. Understanding the factors that determine the emergence of upwelling irradiance from submerged plant canopies will be instrumental in creating remote sensing algorithms necessary to develop global inventories of submerged aquatic vegetation and protect these critical coastal resources (Dierssen et al. 2003).

\section{Material and methods}

The model-The model consisted of three modules simulating (i) vertical canopy architecture and leaf geometry, (ii) irradiance distribution within the simulated seagrass canopy, and (iii) canopy photosynthesis resulting from light ab- sorption by the leaves. The optical medium (canopy plus water column) was divided into a vertical series of planeparallel, horizontally homogeneous slabs of finite thickness $(\Delta z)$. Optical properties of each layer were based on canopy architecture, leaf optical properties, and the optical properties of the water column. Depth incremented positively downward, so that $z=0$ represented the top layer of the submerged seagrass canopy. The parenthetical notation $(\lambda$, $z$ ) denotes wavelength and/or depth dependence of the specified terms. Symbol definitions and dimensions are provided in Table 1.

Module i: Vertical canopy architecture and leaf geometry-A mathematical description of canopy architecture and leaf orientation was derived from morphometric analysis of 35 seagrass populations and some geometric reasoning. Leaf size-frequency distribution and shoot-specific leaf area were measured using shoots collected from 32 turtlegrass (Thalassia testudinum Banks ex König) populations near Lee Stocking Island, Bahamas (LSI) and three eelgrass (Zostera marina L.) populations from California and Washington, USA (Table 2). Shoot density was determined at each site by direct counts of all shoots within twenty randomly located $0.1-\mathrm{m}^{2}$ quadrats. One shoot was collected from each quadrat for detailed measurement of shoot morphology and leaf optical properties. Lengths of all leaves on each shoot were measured to the nearest millimeter with a plastic meter tape. Leaf widths were measured to the nearest $0.01 \mathrm{~mm}$ using a digital caliper. Shoot-specific leaf area $\left(L_{s}\right)$ was calculated as the sum of the one-sided area (length $X$ width) of all leaves on each shoot. The vertical distribution of leaf biomass within each canopy was determined from the respective leaf length-frequency distributions assuming that leaves were vertically oriented and originated at the seafloor. Leaf area index $(L)$ for the entire canopy was defined as the product of the shoot density and the one-sided leaf area per shoot $\left(L_{s}\right)$. It was distributed through the canopy as a function of the relative amount of biomass $[B(z)]$, such that $l(z)$ represented the leaf area index at depth $z$ :

$$
l(z)=L \times B(z)
$$

The relative biomass $[B(z)]$ was distributed vertically as a sigmoid function of the percentage of biomass at the base of the canopy $(\psi)$, the height $[h(z)]$ above the seabed, an intermediate point $(I)$ within the canopy, and a shape factor $(s)$ :

$$
B(z)=\frac{\psi}{1+\left[\frac{h(z)}{I}\right]^{s}}
$$

Values for $\psi, I$, and $s$ were fitted to vertical biomass distributions derived from leaf size-frequency data for each population (Table 2) using a least-squares minimization algorithm employing an iterative, quasi-Newton procedure for nonlinear estimation implemented in Statistica (Rel. 5.1, (c) 1997 Statsoft).

Although phytoplankton respond to the submarine light field as scalar irradiance collectors, seagrass leaves are flat, straplike structures that behave more like plane irradiance 
Table 1. List of model symbols, their definitions, and dimensions. Parenthetic notation of $\lambda$ and $z$ indicates that the quantity is wavelength $(\lambda)$ and/or depth $(z)$ dependent.

\begin{tabular}{|c|c|c|}
\hline Symbol & Definition & Dimensions \\
\hline \multicolumn{3}{|c|}{ Fundamental quantities } \\
\hline$T$ & Daylength & $\mathrm{s} \mathrm{d}^{-1}$ \\
\hline$\theta$ & Polar angle & degrees \\
\hline$\mu$ & Cosine of polar angle & dimensionless \\
\hline$z$ & Depth within the canopy & $\mathrm{m}$ \\
\hline$\Delta_{z}$ & Vertical thickness of canopy layers & $\mathrm{m}$ \\
\hline \multicolumn{3}{|c|}{ Canopy architecture properties } \\
\hline$B(z)$ & Biomass fraction in layer $z$ & dimensionless \\
\hline$\beta$ & Nadir bending angle of the seagrass canopy & degrees \\
\hline$h_{m}$ & Maximum canopy height & $\mathrm{m}$ \\
\hline$h_{c}$ & Realized canopy height & $\mathrm{m}$ \\
\hline$h(z)$ & Height above the seabed & $\mathrm{m}$ \\
\hline$I$ & Intermediate height of sigmoid biomass distribution & $\mathrm{m}$ \\
\hline$L$ & Canopy leaf area index & $\mathrm{m}^{2}$ leaf $\mathrm{m}^{-2}$ seabed \\
\hline$L_{s}$ & Leaf area per shoot & $\mathrm{m}^{2}$ leaf shoot ${ }^{-1}$ \\
\hline$l(z)$ & Leaf area index at depth $z$ & $\mathrm{~m}^{2}$ leaf $\mathrm{m}^{-2}$ seabed \\
\hline$l_{p}(z)$ & Horizontally projected leaf area at depth $z$ & $\mathrm{~m}^{2}$ leaf $\mathrm{m}^{-2}$ seabed \\
\hline$t_{L}$ & Leaf thickness & $\mathrm{m}$ \\
\hline$s$ & Shape factor for sigmoid biomass distribution & dimensionless \\
\hline$\psi$ & Percent of canopy biomass at the seabed & \\
\hline \multicolumn{3}{|c|}{ Radiometric quantities } \\
\hline$E_{d}(\lambda, z)$ & Downwelling plane irradiance transmitted through layer $z$ & quanta $\mathrm{m}^{-2} \mathrm{~nm}^{-1}$ \\
\hline$E_{u}(\lambda, z)$ & Upwelling plane irradiance transmitted through layer $z$ & quanta $\mathrm{m}^{-2} \mathrm{~s}^{-1} \mathrm{~nm}^{-1}$ \\
\hline \multicolumn{3}{|c|}{ Inherent optical properties } \\
\hline$a_{L}(\lambda)$ & Leaf absorption coefficient & $\mathrm{m}^{-1}$ of leaf thickness \\
\hline$A_{L}(\lambda)$ & Leaf-specific absorptance & dimensionless \\
\hline$D(\lambda)$ & Leaf-specific absorbance & dimensionless \\
\hline$R_{L}(\lambda)$ & Leaf reflectance & dimensionless \\
\hline$R_{b}(\lambda)$ & Seabed reflectance & dimensionless \\
\hline$R_{d}(\lambda, z)$ & Canopy reflectance of downwelling irradiance & dimensionless \\
\hline$R_{u}(\lambda, z)$ & Canopy reflectance of upwelling irradiance & dimensionless \\
\hline \multicolumn{3}{|c|}{ Apparent optical properties } \\
\hline$K_{d}(\lambda)$ & Water column attenuation of downwelling irradiance & $\mathrm{m}^{-1}$ \\
\hline$K_{u}(\lambda)$ & Water column attenuation of upwelling irradiance & $\mathrm{m}^{-1}$ \\
\hline $\bar{\mu} d(z)$ & Average cosine of downwelling irradiance & dimensionless \\
\hline $\bar{\mu}_{u}(z)$ & Average cosine of upwelling irradiance & dimensionless \\
\hline \multicolumn{3}{|c|}{ Photosynthetic properties } \\
\hline $\operatorname{PUR}(z)$ & Photosynthetically used irradiance in layer $z$ & quanta absorbed $/\left(\mathrm{m}^{2}\right.$ leaf $\left.\mathrm{s}\right)$ \\
\hline$\phi_{p}$ & Light-use efficiency, scaled to $P_{m}$ & $\left(\mathrm{~m}^{2}\right.$ leaf $\left.\mathrm{s}\right) /$ quanta absorbed \\
\hline$P_{i}(z)$ & Biomass-specific photosynthesis in layer $z$, scaled to $P_{m}$ & dimensionless \\
\hline$P_{c}$ & Depth-integrated biomass-specific photosynthesis, scaled to $P_{m}$ & dimensionless \\
\hline$P_{d}$ & Daily integrated biomass-specific photosynthesis, scaled to $P_{m}{ }^{m}$ & $\mathrm{~s}_{\text {day }}^{-1}$ \\
\hline
\end{tabular}

collectors (see Kirk 1994, pp. 6-12 and/or Mobley 1994, pp. 24-29 for a discussion of the geometric relationships between plane and scalar irradiance). Consequently, light absorption and reflection by the canopy are affected by the orientation of leaves relative to the incident light field, in addition to their optical properties and total area. Correcting $l(z)$ for leaf orientation requires calculating the horizontally projected leaf area or silhouette, $\left[l_{p}(z)\right]$, as a function of the nadir bending angle $(\beta)$ (Fig. 1A):

$$
l_{p}(z)=l(z) \sin \beta
$$

The horizontally projected leaf area $\left[l_{p}(z)\right]$ requires further correction for the angular distribution of downwelling irra- diance. The cosine law defines this correction as $\left[l_{p}(z)\right] / \cos \theta$ for a collimated beam (Fig. 1B), where $\theta$ represents the zenith angle of the beam incident on $l_{p}(z)$ (Mobley 1994, p. $25)$. Although downwelling light is not collimated in natural waters, its angular distribution can be approximated by the average cosine, denoted as $\bar{\mu}_{d}$ (Kirk 1994). Thus, substituting $\bar{\mu}_{d}$ for $\cos \theta$ allows the ratio $\left[l_{p}(z)\right] /\left[\bar{\mu}_{d}(z)\right]$ to approximate the average geometric relationship between seagrass leaves and downwelling irradiance.

Module ii: Two-flow irradiance distribution-In addition to geometry, the distribution of irradiance within the canopy is determined by the combined optical properties of the sea- 


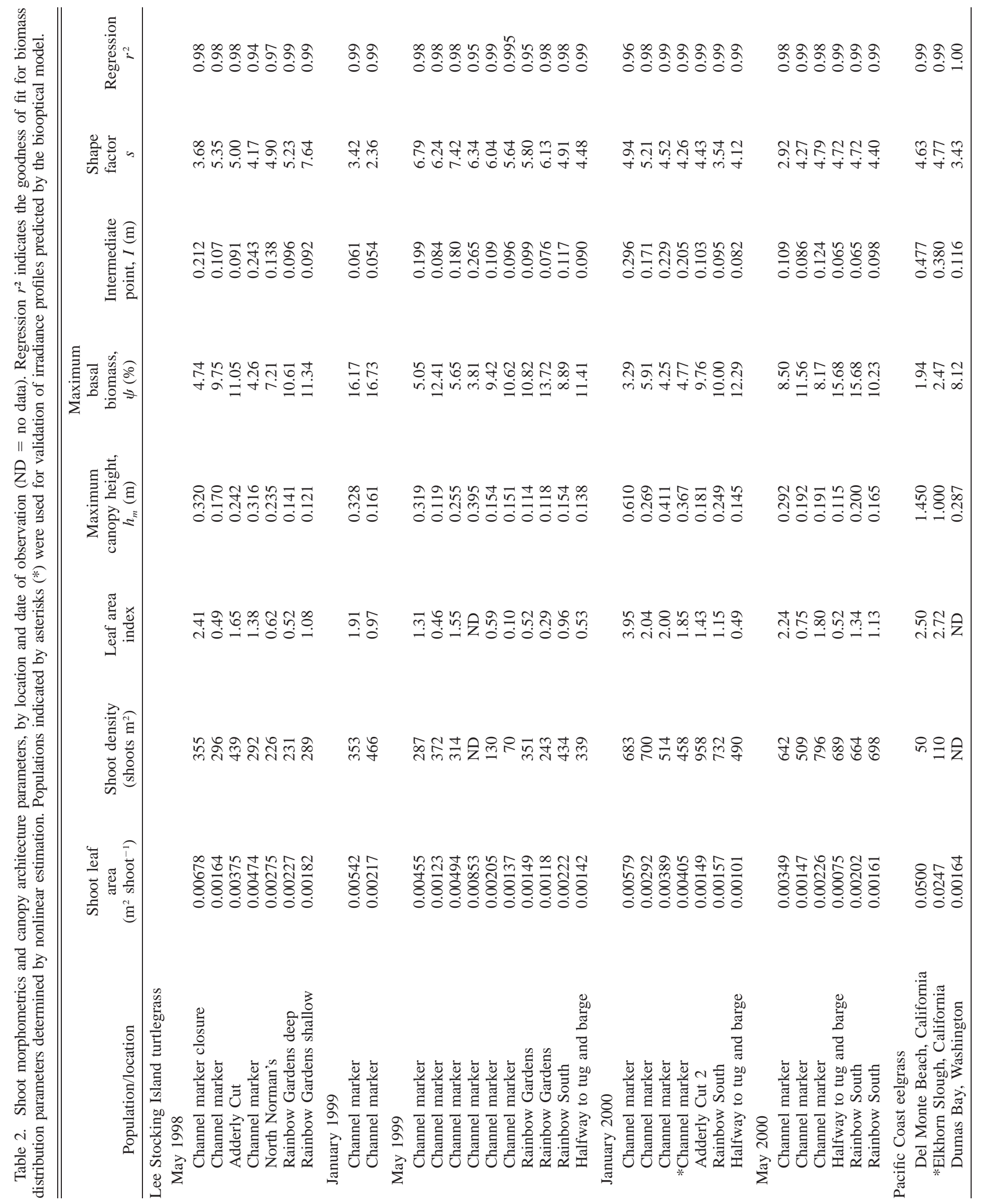



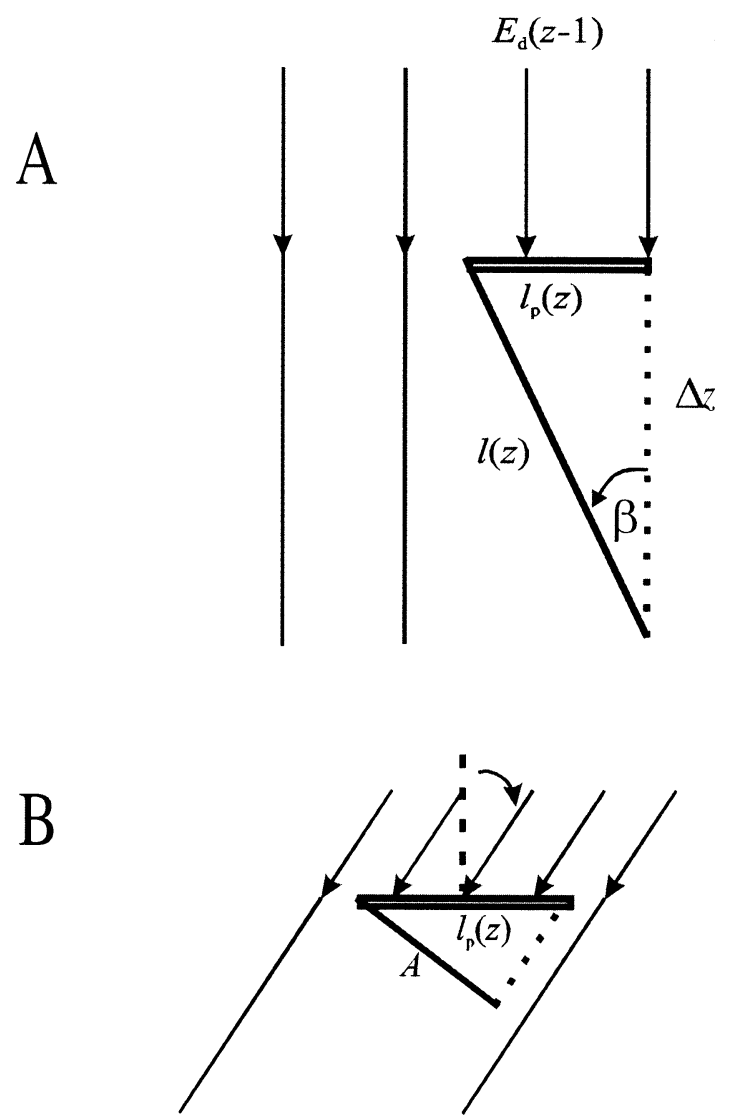

grass leaves and the surrounding water column. Leaf optical properties were derived from in vivo absorption and reflectance spectra of seagrass leaves measured at $0.5-\mathrm{nm}$ resolution (2-nm slit width) using a Shimadzu 2101UV-PC scanning spectrophotometer fitted with an integrating sphere that permits accurate measurement of the scattered radiant flux emanating from turbid samples (e.g., leaves). Absorbance was measured by placing leaf samples at the entrance so that all light transmitted through the leaf was captured by the sphere for detection by the photomultiplier tube. Leaf reflectance was measured by placing the leaf sample at the back of the sphere and capturing all the light scattered backward from the leaf surface into the sphere. Optical properties of 377 turtlegrass leaves were measured using freshly collected shoots from 32 populations near LSI (Table 2). The eelgrass spectra were created from 105 leaf measurements using plants collected from Del Monte Beach and Elkhorn Slough, both in Monterey Bay, California. Leaves were separated into numbered age classes based on their length and position within the shoot. Spectrophotometric leaf absorbance $[D(\lambda)]$ and reflectance $\left[R_{L}(\lambda)\right]$ were measured after removing any epiphytes by gently scraping both sides of each leaf with a razor blade. Spectrophotometric absorbances of the clean leaves $[D(\lambda)]$ were converted to raw absorptances $\left[A_{\text {raw }}(\lambda)\right]$ according to Kirk (1994):

$$
A_{\text {raw }}(\lambda)=1-10^{-D(\lambda)}
$$

The raw absorptances were corrected for reflectance losses to obtain true leaf absorptances

$$
A_{L}(\lambda)=A_{\text {raw }}(\lambda)-R_{L}(\lambda)
$$

and transformed into absorption spectra, where $t_{L}$ was the cross-sectional thickness of the leaf:

$$
a_{L}(\lambda)=\frac{-\ln \left[1-A_{L}(\lambda)\right]}{t_{L}}
$$

Average absorption spectra for turtlegrass and eelgrass leaves were calculated from the individual leaf measurements, weighted by the fractional area of each leaf age class in each data set.

The downwelling plane irradiance emerging from layer $(z)$ within the canopy was calculated by numerical approximation of the Lambert-Beer Law:

$$
\begin{aligned}
E_{d}(\lambda, z)= & E_{d}(\lambda, z-1)\left[1-R_{d}(\lambda, z)\right] \\
& \times \exp \left[-a_{L}(\lambda) t_{L} \frac{l_{p}(z)}{\bar{\mu}_{d}(z)}-K_{d}(\lambda, z) \Delta z\right]
\end{aligned}
$$

where $E_{d}(\lambda, z-1)$ was the downwelling plane irradiance incident on layer $z$. The loss term $\left[1-R_{d}(\lambda, z)\right]$ accounted for upward reflection of downwelling plane irradiance by each canopy layer $(z) . R_{d}(\lambda, z)$ was determined from the spectrophotometrically measured leaf reflectance $\left[R_{L}(\lambda)\right]$, corrected

Fig. 1. Geometric relationships between leaf area $[l(z)]$, horizontally projected leaf area $\left[l_{p}(z)\right]$, and plane irradiances $\left[E_{d}(\lambda, z)\right.$, $\left.E_{u}(\lambda, z)\right]$ defined by the cosine law. (A) The horizontally projected leaf area $\left[l_{p}(z)\right]$ is proportional to $\sin \beta$, the nadir bending angle of the leaf. (B) The downwelling irradiance incident on $l_{p}(z)$ is related to the length of $A$, which is proportional to $\cos \theta$, the zenith angle of incident irradiance for a collimated beam. (C) Schematic representation of the two-flow irradiance streams calculated in the model.

Vertical arrows represent the two main flow components $E_{d}(\lambda, z)$ and $E_{u}(\lambda, z)$. Diagonal arrows account for reflection between $E_{d}(\lambda, z)$ and $E_{u}(\lambda, z)$. 
by the horizontal silhouette of leaf area and the average cosine of downwelling irradiance $\left[l_{p}(z)\right] /\left[\bar{\mu}_{d}(z)\right]$ :

$$
R_{d}(\lambda, z)=R_{L}(\lambda) \frac{l_{p}(z)}{\bar{\mu}_{d}(z)}
$$

Light absorption by the seagrass canopy present in layer $z$ was accounted for by $a_{L}(\lambda) t_{L}\left\{\left[l_{p}(z)\right] /\left[\bar{\mu}_{d}(z)\right]\right\}$, which scaled the leaf absorption coefficient $\left[a_{L}(\lambda)\right]$ to the thickness of the leaf $\left(t_{L}\right)$, and the geometric correction term $\left[l_{p}(z)\right] /\left[\bar{\mu}_{d}(z)\right]$. $K_{d}(\lambda, z)$ was the coefficient of diffuse attenuation for downwelling plane irradiance for the water column, including its dissolved and suspended components, but without the seagrass leaves. Leaf thickness was $250 \mu \mathrm{m}$. The thickness of each layer $z$ was defined by $\Delta z$.

Radiative transfer in plant canopies is not well simulated by models that assume isotropic scattering of all light within the bulk canopy. Unfortunately, the scattering properties of plant leaves, required for the development of more mechanistic models, are poorly known. Reasonably anisotropic scattering within plant canopies, however, can be achieved when the radiance distribution of transmittance and reflectance from individual leaf surfaces are assumed to be hemispherically isotropic (bi-Lambertian) about the leaf normal (Shultis and Myneni 1988). This simple, but apparently robust, assumption was implemented here by adjusting the average cosine for downwelling irradiance to become incrementally more isotropic [i.e., $\bar{\mu}_{d}(z) \rightarrow 0.5$ ] in each layer as a fraction of the transmitted irradiance was scattered by the horizontally projected leaf area in each layer:

$$
\bar{\mu}_{d}(z)=\bar{\mu}_{d}(z-1)-\left\{\left[\bar{\mu}_{d}(z-1)-0.5\right] l_{p}(z)\right\}
$$

The notation $(z-1)$ refers to the value of $\bar{\mu}_{d}$ entering layer $(z)$. Water column effects on $\bar{\mu}_{d}(z)$ were ignored because the average cosine changed by $<0.05 \mathrm{~m}^{-1}$ in Hydrolight (Mobley 1989) simulations performed without a plant canopy using water column IOPs representative of the sites simulated here. By comparison, the plant canopy reduced $\bar{\mu}_{d}(z)$ by 0.35 over that same distance, an order of magnitude larger effect. The downwelling attenuation coefficient $\left[K_{d}(\lambda, z)\right]$, however, was adjusted for canopy induced changes in $\bar{\mu}_{d}(z)$ based on the assumption that $K_{d}(\lambda, z) \propto 1 /\left[\bar{\mu}_{d}(z)\right]$ (see pp. 278-279, Eqs. 5.65 and 5.66 in Mobley 1994):

$$
K_{d}(\lambda, z)=K_{d}(\lambda, z-1) \frac{\bar{\mu}_{d}(z-1)}{\bar{\mu}_{d}(z)}
$$

The upwelling plane irradiance at the base of the canopy was calculated as the product of downwelling irradiance reaching the seabed $\left[E_{d}(\lambda, b)\right]$ and the seabed reflectance $\left[R_{b}(\lambda)\right]$ :

$$
E_{u}(\lambda, b)=E_{d}(\lambda, b) R_{b}(\lambda)
$$

The irradiance reflected from the seabed $\left[E_{u}(\lambda, b)\right]$ was then propagated upward through the canopy in a manner similar to that for downward propagation of $E_{d}(\lambda, 0)$. The upward flux incident on layer $(z)$ was calculated by adding the downwelling irradiance reflected upward by layer $(z+1)$ to the upwelling irradiance transmitted through layer $(z+1)$ (Fig. $1 \mathrm{C})$. The resulting upward flux was attenuated through reflection and absorption by the plant canopy, combined with attenuation by the water column:

$$
\begin{aligned}
E_{u}(\lambda, z)= & \left\{\left[E_{d}(\lambda, z) R_{d}(\lambda, z+1)\right]+E_{u}(\lambda, z+1)\right\} \\
& \times\left[1-R_{u}(\lambda, z)\right] \\
& \times \exp \left[-a_{L}(\lambda) t_{L} \frac{l_{p}(z)}{\bar{\mu}_{u}}-K_{u}(\lambda) \Delta z\right]
\end{aligned}
$$

The reflected loss of upwelling light was calculated as [1 $R_{u}(\lambda, z)$ ], where

$$
R_{u}(\lambda, z)=R_{L}(\lambda) \frac{l_{p}(z)}{\bar{\mu}_{u}}
$$

and $\left[l_{p}(z)\right] /\left[\bar{\mu}_{u}(z)\right]$ represented the geometric correction for upwelling plane irradiance. Since reflectance was assumed to be Lambertian (i.e., equal radiances at all hemispheric angles) from both the seabed and from individual leaves, $\bar{\mu}_{u}$ was unchanged $(=0.5)$ as $E_{u}(\lambda, z)$ propagated upward through the canopy. The water column coefficient for attenuation of upwelling plane irradiance $\left[K_{u}(\lambda)\right]$ was calculated from $K_{d}(\lambda, z)$ incident on the seabed using the same relations assumed for Eq. 10, with the added assumption that the seabed represented a Lambertian reflecting boundary:

$$
K_{u}(\lambda, b)=K_{d}(\lambda, b) \frac{\bar{\mu}_{d}(b)}{0.5}
$$

In summary, Eqs. 7 and 12 describe the two-flow model of plane irradiance distribution for the seagrass canopy embedded in an optically active water column. Downwelling irradiance decreased with depth due to absorption and scattering into $E_{u}$ and increased by scattering of $E_{u}$ into $E_{d}$. The upwelling irradiance increased by scattering of $E_{d}$ into $E_{u}$ and decreased by absorption and scattering into $E_{d}$ (Fig. 1C).

Module iii: Canopy photosynthesis-Canopy photosynthesis was driven using light absorbed by photosynthetic pigments within the seagrass leaves. Photosynthetic absorptance $\left[A_{p}(\lambda)\right]$ was calculated by removing nonspecific absorption from $A_{L}(\lambda)$ (defined in Eq. 5):

$$
A_{p}(\lambda)=A_{L}(\lambda)-A_{L}(750)
$$

The photosynthetically used radiation $[\operatorname{PUR}(z)]$ was then calculated for each layer $z$ as

$\operatorname{PUR}(z)=\sum_{\lambda} A_{p}(\lambda) l_{p}(z)\left[\frac{E_{d}(\lambda, z-1)}{\bar{\mu}_{d}(z-1)}+\frac{E_{u}(\lambda, z+1)}{\bar{\mu}_{u}}\right]$

after converting $E_{d}$ and $E_{u}$ from energy (Watts) to quantum units:

$$
\text { quanta } \mathrm{s}^{-1}=\text { Watts } \times \lambda 5.03 \times 10^{15}
$$

Instantaneous biomass-specific photosynthesis within layer $(z)$ was expressed using a cumulative one-hit Poisson function (Falkowski and Raven 1997) in which both $P_{i}(z)$ and the photosynthetic light use efficiency $\left(\phi_{p}\right)$ were scaled to the maximum rate of light-saturated, biomass-specific gross photosynthesis to provide a general context for evaluating the effects of canopy orientation and leaf optical properties on the potential for photosynthetic light use

$$
P_{i}(z)=B(z)\left\{1-\exp \left[-\phi_{p} \mathrm{PUR}(z)\right]\right\}
$$

In normalizing the photosynthesis versus irradiance $(P$ vs. 
$E$ ) model to $P_{m}$, the light use efficiency $\left(\phi_{p}\right)$ became an aggregate term with units of $\left(\mathrm{m}^{2}\right.$ leaf $\left.\mathrm{s}\right) /$ (quanta absorbed) and $P_{i}(z)$ became a dimensionless factor that ranged from 0 to $B(z)$. The normalized rate of biomass-specific instantaneous photosynthesis for the whole canopy $\left(P_{c}\right)$ was then determined by summation of $P_{i}(z)$ over $z$

$$
P_{c}=\sum_{z} P_{i}(z)
$$

and ranged from 0 to 1 . The daily integrated biomass-specific photosynthesis of the canopy was calculated as

$$
P_{d}=\sum_{z} B(z)\left\{1-\exp \left[-0.67 \phi_{p} \operatorname{PUR}(z)\right]\right\} T
$$

The length of the daily photoperiod was defined by $T$ and the value 0.67 was an empirically determined integration constant (Zimmerman et al. 1996). Thus, $P_{d}$ was dimensionalized in units of time, making it mathematically equivalent to the number of hours of light-saturated photosynthesis $\left(H_{\text {sat }}\right)$ experienced by the canopy in a day, but without the simplifying assumptions of a square-wave pattern of light availability that has caused theoretical concern with the originally formulated $H_{\text {sat }}$ model (reviewed in Zimmerman et al. 1994 and Burd and Dunton 2001). Calculation of the daily integral by Eq. 20, however, requires two key assumptions: (i) downwelling irradiance at the top of the seagrass canopy must vary sinusoidally over the day, and (ii) the value of $\operatorname{PUR}(z)$ calculated from Eq. 16 must represent the photosynthetically used irradiance at noon. $P_{d}$ also can be calculated by numerical integration of Eqs. 18 and 19 from continuous measures of irradiance if the daily cycle is not sinusoidal due to variations in, e.g., cloud cover, tide height, or water column turbidity (Zimmerman et al. 1994). Model investigations incorporating whole plant respiration and daily carbon balance will be explored in a future paper.

Model parameterization-Seabed reflectance spectra $\left[R_{b}(\lambda)\right]$ were obtained from laboratory and field measures. The laboratory-measured reflectance of ooitic carbonate sand from LSI was provided by Louchard et al. (2003). Spectra for turtlegrass leaf litter from LSI, and siliciclastic sand and mud sediments from Monterey Bay, were obtained from in situ measurements using a diver-operated benthic biooptical spectroradiometer (DOBBS). The DOBBS consisted of a radiometrically calibrated three-channel HydroRad (HOBI Labs) mounted on a portable frame that allowed for easy manipulation and positioning of irradiance collectors underwater. The three spectroradiometer channels were fitted with optical fibers and cosine-corrected plane irradiance collectors. Two collectors were mounted on an adjustable wand that could be positioned anywhere from 0 to $1.10 \mathrm{~m}$ above the sea floor. One collector on the wand measured downwelling spectral irradiance $\left[E_{d}(\lambda, z)\right]$; the other measured upwelling spectral irradiance $\left[E_{u}(\lambda, z)\right]$. A third collector measured downwelling spectral irradiance $\left[E_{\mathrm{d} \text {-ref }}(\lambda)\right]$ at a fixed height $(1 \mathrm{~m})$ above the sea floor. Wavelength registration among the three channels was accomplished by interpolating the raw spectra from each sensor (nominally $0.45-\mathrm{nm}$ resolution) to 1-nm intervals using a cubic spline. The registered spectra were smoothed using a 20-nm running average. Each record was the average of ten spectra collected sequentially over a 10 to $30 \mathrm{~s}$ sample period. Ten to twenty separate measurements were obtained over mats of dead turtlegrass leaf litter at Leaf Cay near LSI (2 $\mathrm{m}$ depth); over bare siliciclastic sand at Del Monte Beach, California (8 m depth); and over bare mud in Elkhorn Slough, California $(2 \mathrm{~m}$ depth). Average spectra for each substrate type were used to parameterize $R_{b}(\lambda)$ for different simulations presented here.

Water column optical properties - Values of $K_{d}(\lambda, 0)$ and $\bar{\mu}_{d}(0)$ at the tops of the seagrass canopies were calculated by $\mathrm{R}$. Maffione (HOBI Labs) with the radiative transfer program Hydrolight (Ver. 4.0, ${ }^{\circ}$ C. Mobley) using inherent optical properties (IOPs) of the water column measured at both sites. Water column IOPs from LSI, measured using a diveroperated $a c-9$ submersible spectrophotometer (Wetlabs, Inc.) (Zaneveld et al. 2001), were provided by R. Zaneveld and E. Boss (Oregon State University) for the turtlegrass simulation. Water column IOPs for the eelgrass simulation were measured by laboratory spectroscopy of a water sample collected just below the surface of Elkhorn Slough using a polycarbonate bottle, in conjunction with the DOBBS measurement of submarine irradiance spectra within the seagrass canopy. Spectral beam attenuation of the intact water sample from Elkhorn Slough was measured using a $10-\mathrm{cm}$ cuvette and Shimadzu UV2101 scanning spectrophotometer at a spectral resolution of $0.5 \mathrm{~nm}$. Baseline correction was performed using freshly prepared ultrapure $\left(18 \mathrm{M} \Omega \mathrm{cm}^{-1}\right)$ deionized water. Particle absorption was measured using the filter-pad technique and integrating sphere attachment of the spectrophotometer. Correction for multiple scattering within the GF/F filter pad was performed according to Cleveland and Weidemann (1993). Absorption by dissolved materials was measured in a $10-\mathrm{cm}$ cuvette after filtering the water sample through a $0.22 \mu \mathrm{m}$ Nucleopore membrane filter. Total absorption (without water) was calculated as the sum of particulate and dissolved absorption. The resulting Hydrolightderived values of $\bar{\mu}_{d}(0)$ were 0.88 and 0.80 for the turtlegrass and eelgrass simulations, respectively. Values for $K_{d}(550,0)$ at the top of the seagrass canopies were 0.12 and 1.28 for the turtlegrass and eelgrass simulations, respectively.

Boundary conditions-Input data provided the following boundary conditions and initial parameterizations: downwelling spectral irradiance incident at the top of the seagrass canopies $\left[E_{d}(\lambda, 0)\right]$ measured by the DOBBS; the spectral coefficient of downwelling diffuse attenuation $\left[K_{d}(\lambda, 0)\right]$ and average cosine $\left[\bar{\mu}_{d}(0)\right]$ calculated from water column IOPs using Hydrolight; seabed reflectance $\left[R_{b}(\lambda)\right]$; seagrass leaf absorptances, absorption coefficients, and reflectances $\left[A_{L}(\lambda), a_{L}(\lambda), R_{L}(\lambda)\right]$; and canopy architecture $[L, B(z)]$. Leaf bending angle $(\beta)$ was measured from digitized video images of a turtlegrass canopy near LSI at slack tide. Unless otherwise specified, $\beta=5^{\circ}$ for all simulations described here. The model then computed the horizontally projected leaf area in each layer $\left[l_{p}(z)\right]$; vertical profiles of spectral irradiance $\left[E_{d}(\lambda, z), E_{u}(\lambda, z)\right]$; photosynthetic absorptance $\left[A_{p}(\lambda)\right]$; and biomass-specific photosynthesis $\left[P_{i}(z), P_{c}\right.$, and $\left.P_{d}\right]$. Thickness $(\Delta z)$ of each canopy layer was $0.01 \mathrm{~m}$. Prelimi- 

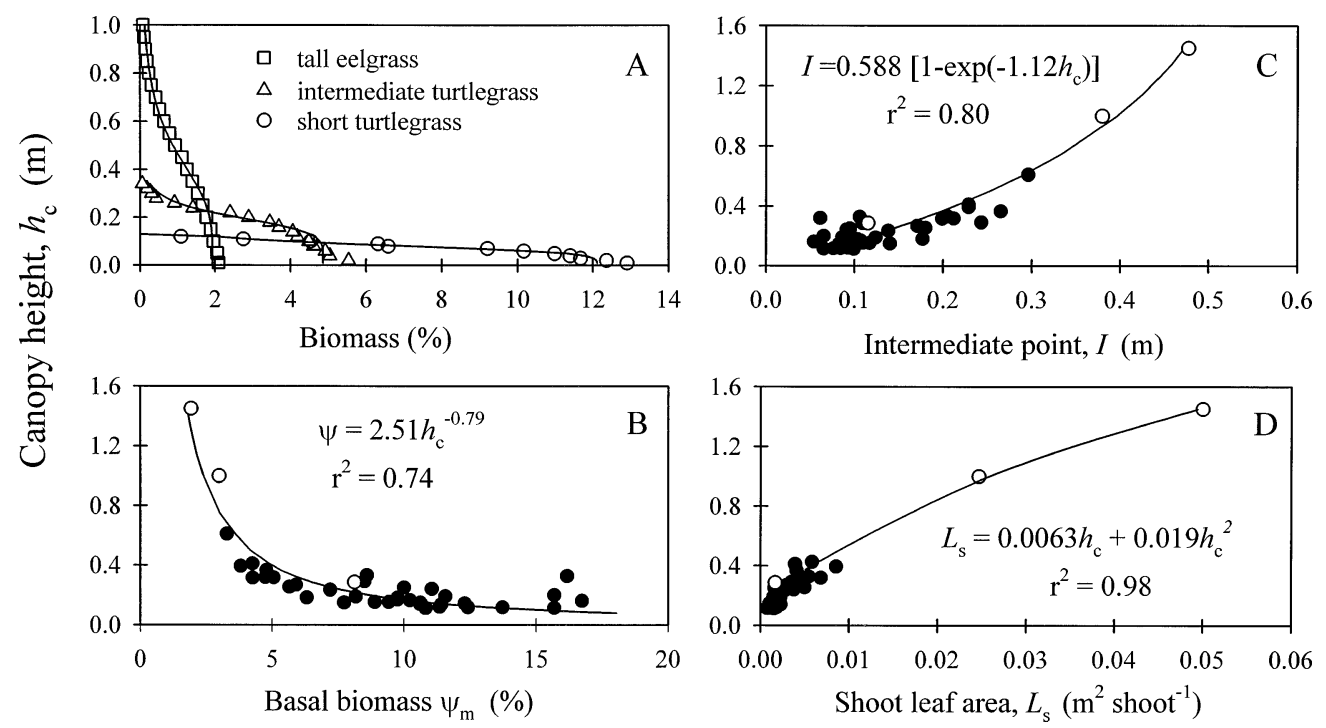

Fig. 2. (A) Vertical distribution of biomass for three representative seagrass populations. Symbols indicate the measured biomass profiles determined from analysis of leaf length-frequency distributions. Lines indicate sigmoid models of those biomass distributions derived specifically for each population. Although the tall eelgrass population extended to $1.45 \mathrm{~m}$, the plot was truncated at $1 \mathrm{~m}$ to avoid visual compaction of the plots of intermediate and short turtlegrass canopies. (B) Relationship between canopy height $\left(h_{c}\right)$ and the maximum percentage of biomass at the base of the canopy $(\psi)$. (C) Relationship between canopy height $\left(h_{c}\right)$ and the intermediate point $(I)$ of the sigmoid curve within the canopy. (D) Relation between canopy height $\left(h_{c}\right)$ and shoot leaf area $\left(L_{s}\right)$. Symbols in plots B, C, and D represent parameter values derived for the populations listed in Table 2. Filled circles, turtlegrass populations; open circles, eelgrass populations.

nary runs using a $\Delta z$ of $0.001 \mathrm{~m}$ affected model predictions by $<0.1 \%$ relative to runs performed at $0.01-\mathrm{m}$ resolution.

Validation of in-canopy irradiance distributions-Model accuracy was evaluated by calculating the spectrally integrated root mean square (rms) difference between irradiances predicted by the model and measured by the DOBBS, normalized to the measured profiles:

$$
\begin{aligned}
& \text { rms difference }(\%) \\
& =100 \sqrt{\frac{\sum_{\lambda}\left(\frac{\text { modeled }- \text { measured }}{\text { measured }}\right)^{2}}{n}}
\end{aligned}
$$

Simulations presented here consisted of a turtlegrass canopy at the LSI channel marker in January 2000 (4 m depth) and an eelgrass canopy at Elkhorn Slough in April 2000 (1.5 m depth). Both populations are indicated by asterisks in Table 2. The in situ measurements were performed near local noon at slack tide to maximize the irradiance at the top of the canopy and minimize leaf bending due to tidal currents. Shoot densities and vertical biomass distributions at these sites were characterized as described above. Reference $E_{d}(\lambda)$ spectra measured by the DOBBS at a constant height of 1 $\mathrm{m}$ above the seafloor were used to correct vertical profiles of irradiance measured by the wand sensors for temporal changes in $E_{d}(\lambda, 0)$ caused by variation in cloud cover and slight changes in depth of the overlying water column during the acquisition of the vertical profiles (15 to $20 \mathrm{~min}$ ). Signal: noise problems with the DOBBS at energy fluxes below $0.05 \mathrm{~W} \mathrm{~m}^{-2} \mathrm{~nm}^{-1}$ prevented reliable measurement of $E_{u}(\lambda, z)$ below $500 \mathrm{~nm}$ and above $600 \mathrm{~nm}$ within the plant canopies examined here.

\section{Results}

Canopy architecture - Vertical biomass distributions of all seagrass populations, ranging from the $0.114-\mathrm{m}$ tall turtlegrass population at LSI to the $1.45-\mathrm{m}$ tall eelgrass population from Del Monte Beach, were well described by the sigmoid function (Eq. 2). Nonlinear $r^{2}$ was $\geq 0.94$ for all populations (Table 2). Figure $2 \mathrm{~A}$ provides examples of the close agreement between observed and modeled biomass distributions for a very short turtlegrass canopy, a turtlegrass canopy of intermediate height (both from LSI), and a tall eelgrass population from Del Monte Beach in Monterey Bay, California. Analysis of canopy architecture parameterizations among all 35 populations revealed that the percentage of biomass at the seabed $(\psi)$ and the intermediate point $(I)$ and the leaf area per shoot $\left(L_{s}\right)$ could be expressed as a function of canopy height, $h_{c}$, (Figs. 2B to 2D)

$$
\begin{aligned}
\psi & =2.51 h_{c}^{-0.79} \\
I & =0.588\left[1-\exp \left(-1.12 h_{c}\right)\right] \\
L_{s} & =0.0063 h_{c}+0.019 h_{c}^{2}
\end{aligned}
$$

where $h_{c}$ depended on the maximum height of a vertically erect canopy $\left(h_{m}\right)$ and the bending angle $(\beta)$ : 


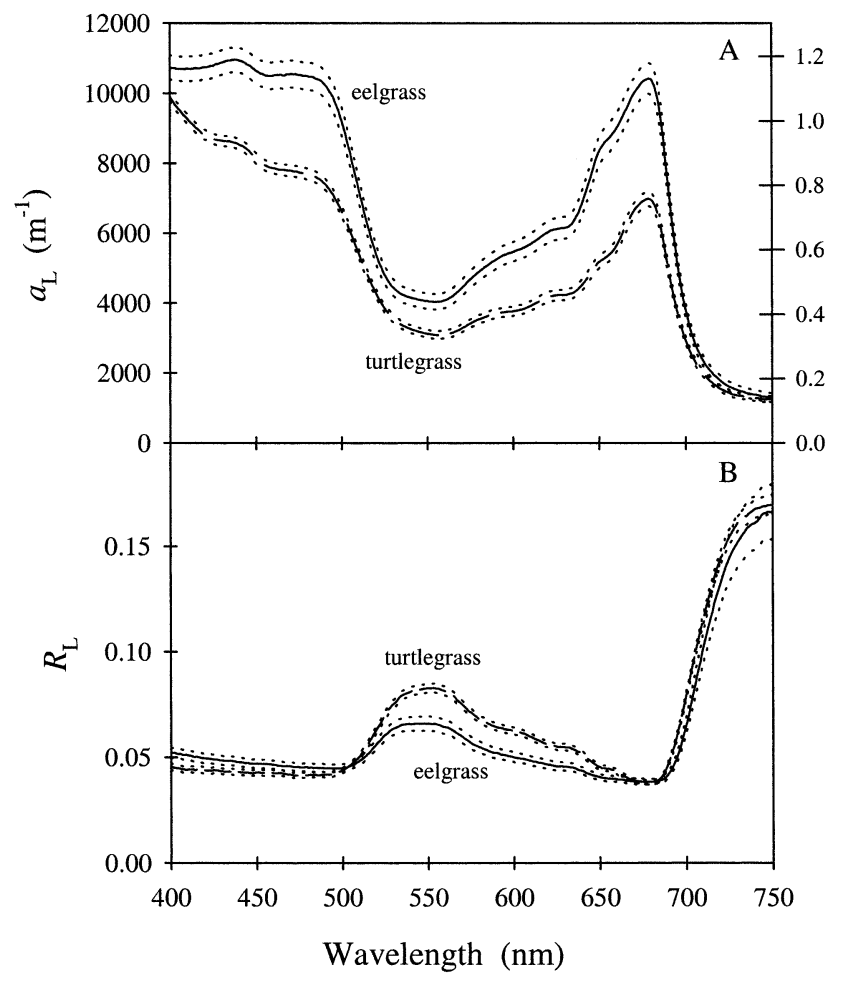

Fig. 3. (A) Absorption spectra of clean turtlegrass and eelgrass leaves. Leaf absorption coefficients $\left(a_{L}\right.$, left vertical axis) were expressed $\mathrm{m}^{-1}$ of leaf thickness. Optical densities, or absorbances $\left(D_{L}\right)$, normalized to the thickness of a single leaf, were scaled on the right vertical axis. (B) Reflectance spectra of clean turtlegrass and eelgrass leaves. Solid lines indicate mean spectra; dotted lines indicate standard errors of the means.

$$
h_{c}=h_{m} \cos \beta
$$

The shape factor $(s)$ in Eq. 2 was not significantly correlated to $h_{c}\left(r^{2}=0.049\right.$, $\mathrm{df}=1$ and 35 , regression $\left.p=0.19\right)$. Consequently, the mean of all individual population estimates $(\bar{s}=4.75$, standard error $=0.20)$ was used to parameterize height-dependent canopy architecture for the sensitivity analyses performed below.

Seagrass leaf optical properties-Leaf absorption and reflectance spectra were qualitatively typical of vascular plant and green algae pigment systems dominated by chlorophylls $a$ and $b$ (Fig. 3). The red edge of the Soret absorption band terminated in a steep shoulder at $490 \mathrm{~nm}$ in both species (Fig. 3A). There was a broad transmission window between 525 and $650 \mathrm{~nm}$ and a narrow absorption peak centered at $678 \mathrm{~nm}$. The absorption coefficient of eelgrass was consistently higher than turtlegrass across the visible portion of the spectrum, but converged with turtlegrass beyond $700 \mathrm{~nm}$. Chl $(a+b)$ concentrations ranged from 1.58 to $2.05 \mathrm{mg} \mathrm{g}^{-1}$ fresh weight in eelgrass leaves from the low light environment of Monterey Bay, and 0.60 to $0.84 \mathrm{mg}$ Chl $(a+b)$ $\mathrm{g}^{-1}$ fresh weight in turtlegrass leaves from the high-light environment around Lee Stocking Island (Cummings and Zimmerman in press).

Reflectances of eelgrass and turtlegrass were indistin-

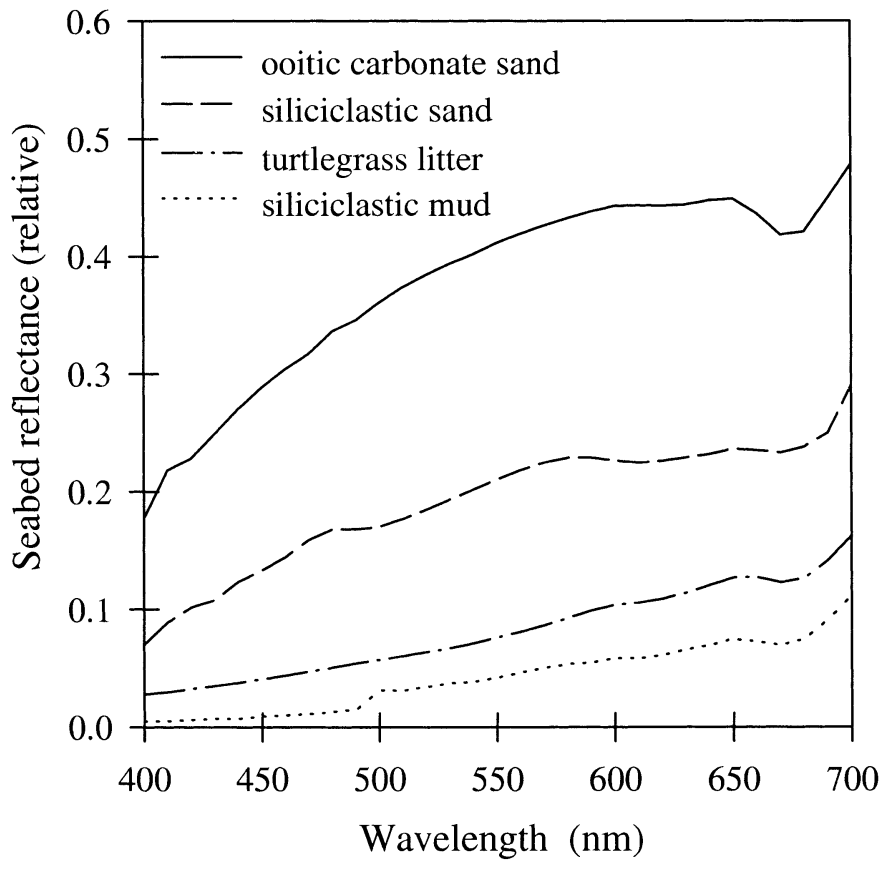

Fig. 4. Reflectance spectra of different constituents used to create the seabed optical boundary for the model.

guishable across most of the spectrum, as indicated by the overlapping standard errors (Fig. 3B). Turtlegrass leaves, however, were more reflective than eelgrass between 525 and $650 \mathrm{~nm}$, probably a consequence of lower pigment content.

Seabed optical properties-Reflectance spectra $\left[R_{b}(\lambda)\right]$ of carbonate, siliciclastic, and leaf litter substrates had similar relative shapes, with $R_{b}(\lambda)$ increasing from blue to red (Fig. 4). All spectra dipped at $680 \mathrm{~nm}$, probably from microalgal pigments on the substrates. Otherwise, the ooitic carbonate sand from LSI was highly reflective at all wavelengths, with a peak reflectance of about 0.45 at $650 \mathrm{~nm}$ (Fig. 4). The reflectance of gray siliciclastic sand from Del Monte Beach (Monterey Bay, California) peaked at about 0.22 at $650 \mathrm{~nm}$, half that of the carbonate sand from LSI. The reflectance of turtlegrass leaf litter from LSI, which was slightly less than half as bright as the siliciclastic sand, peaked at about 0.10 at $650 \mathrm{~nm}$. Reflectance of the estuarine mud from Elkhorn Slough (Monterey Bay, California) was about one-third the brightness of the siliciclastic sand and peaked at about 0.06 at $650 \mathrm{~nm}$.

Validation of in-canopy irradiance profiles-The turtlegrass canopy simulation was based on a moderately dense meadow $\left(h_{c}=0.367 \mathrm{~m}, 458\right.$ shoots $\left.\mathrm{m}^{-2}, L=1.85\right)$ growing at $4 \mathrm{~m}$ depth near the LSI channel marker (Table 2). Seafloor reflectance was constructed from a linear mixture of $65 \%$ turtlegrass leaf litter reflectance and $35 \%$ carbonate sand reflectance. The irradiance spectrum at $0 \mathrm{~m}$ (open circles) represented the boundary condition at the top of the canopy, $3.6 \mathrm{~m}$ below the surface of the water. Both predicted and observed $E_{d}(\lambda, z)$ decreased down through the canopy (Fig. $5 \mathrm{~A})$. Predicted $E_{d}(\lambda, z)$ midway through the canopy $(0.2 \mathrm{~m})$ 


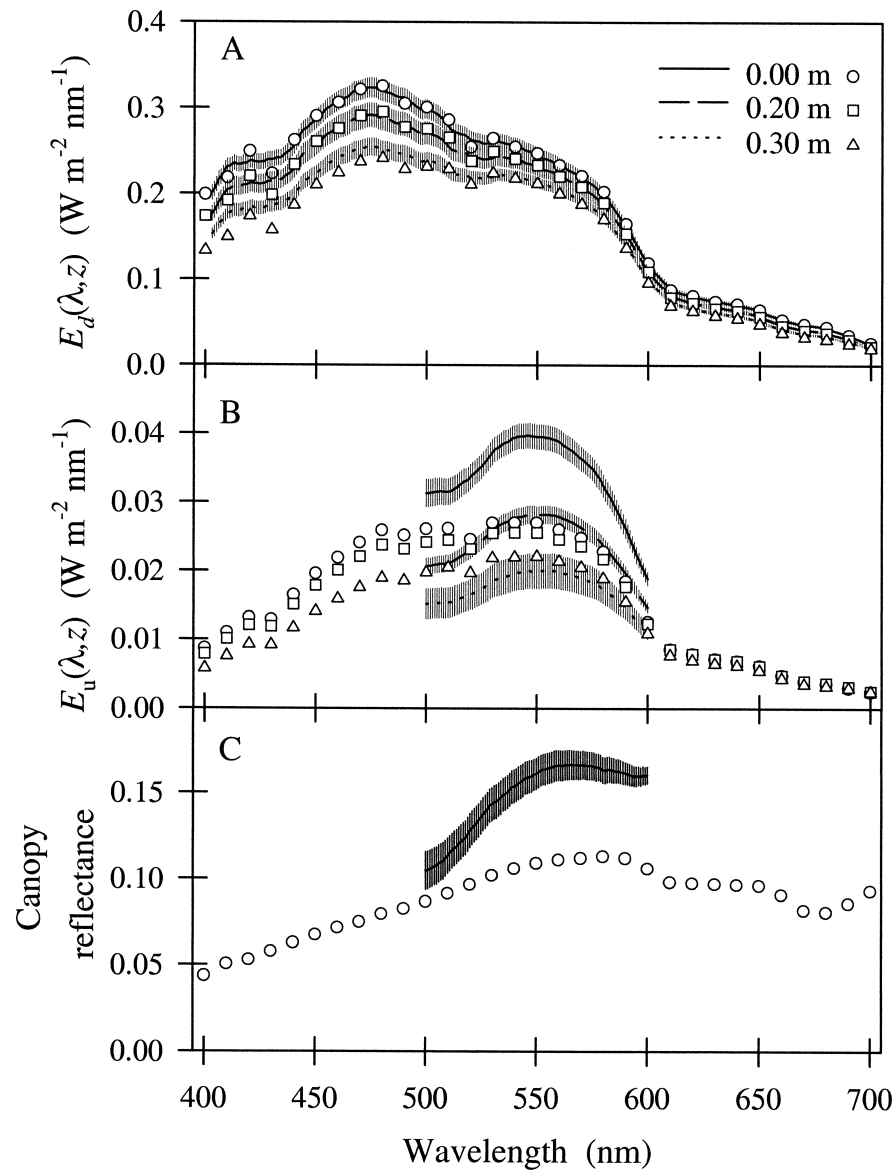

Fig. 5. Measured (lines) and modeled (symbols) irradiance and reflectance spectra of the submarine light field within the turtlegrass canopy at Lee Stocking Island. Depth is indicated relative to the top of the canopy. Vertical bars on the measured spectra represent $\pm 1 \mathrm{SE}$ of the mean for 10 measurements at each depth. Definitions of symbols and lines are the same for all three plots. (A) Downwelling irradiances within the turtlegrass canopy. (B) Upwelling irradiances within the turtlegrass canopy. (C) Irradiance reflectance $\left[E_{u}(\lambda, 0)\right] /\left[E_{d}(\lambda, 0)\right]$ at the top of the turtlegrass canopy.

was within $1.2 \%$ of the DOBBS measurement across the spectrum (DOBBS-normalized rms difference). Model predictions were within $2.5 \%$ of DOBBS measurements at 0.3 $\mathrm{m}$ depth, but the model predicted slightly lower irradiances in the blue (400 to $500 \mathrm{~nm}$ ) relative to DOBBS observations. Even these differences, however, were within 1 standard error of the average measured spectrum.

The intensity of both predicted and observed $E_{u}(\lambda, z)$ increased upward through the canopy, away from the seabed (Fig. 5B). Relatively high noise in the red and blue portions of measured spectra at fluxes below $0.05 \mathrm{~W} \mathrm{~m}^{-2} \mathrm{~nm}^{-1}$ restricted the following comparisons to wavelengths between 500 and $600 \mathrm{~nm}$. Most of the upwelling irradiance emitted from the top of the canopy was reflected from the upper half of the canopy, not the seabed, since the measured amplitude of $E_{u}(\lambda, 0)$ was about twice that of $E_{u}(\lambda, 0.3)$. The measured upwelling spectra were also strongly peaked in the green (525 to $575 \mathrm{~nm}$ ) relative to $E_{d}(\lambda, z)$, which is more consistent with the reflection of light from turtlegrass leaves than the

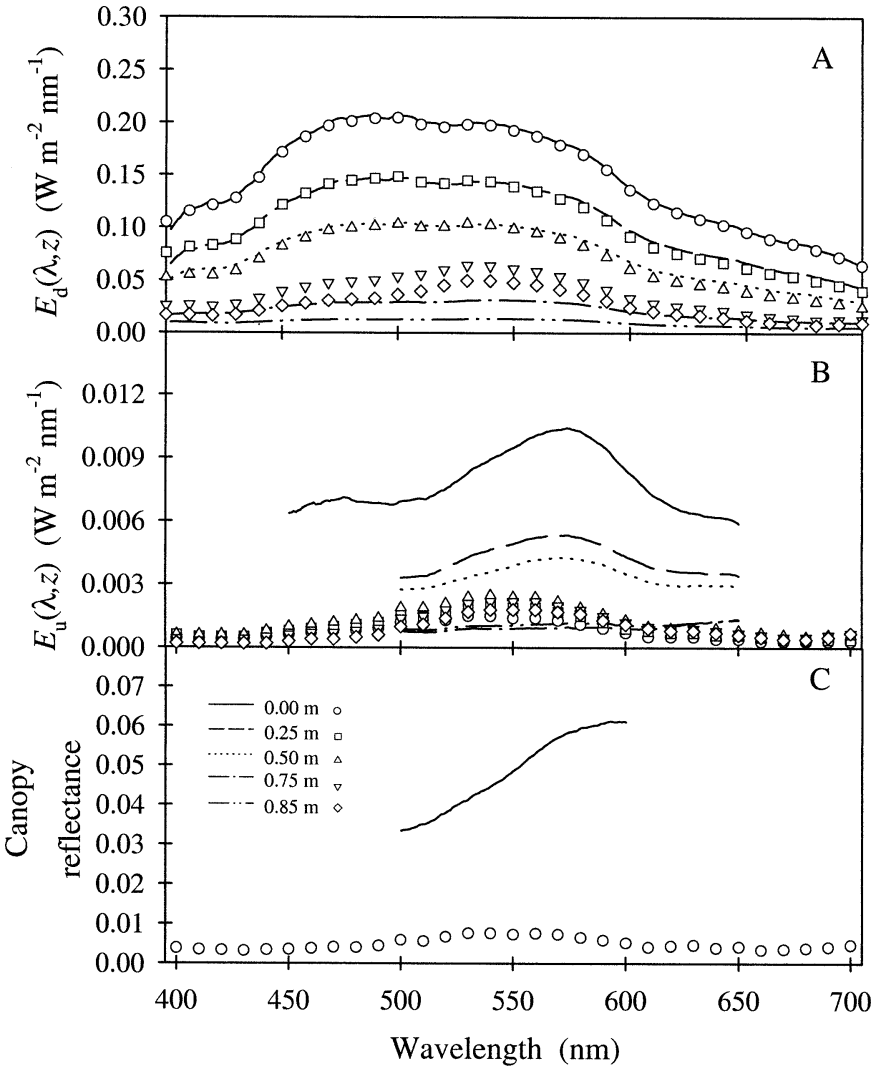

Fig. 6. Measured (lines) and modeled (symbols) irradiance and reflectance spectra of the submarine light field within the eelgrass canopy at Elkhorn Slough. Depth is indicated relative to the top of the canopy. Definitions of symbols and lines are the same for all three plots. (A) Downwelling irradiances within the eelgrass canopy. (B) Upwelling irradiances within the eelgrass canopy. (C) Irradiance reflectance $\left[E_{u}(\lambda, 0)\right] /\left[E_{d}(\lambda, 0)\right]$ at the top of the eelgrass canopy.

white or gray substrate beneath the leaf canopy (Fig. 5B). The spectrum of $E_{u}(\lambda, 0.3)$ predicted by the model was generally higher, but within $18 \%$ (rms difference) of the measured spectrum. The model-generated peak at $550 \mathrm{~nm}$, however, was less pronounced than the measured peak. At 0.2 $\mathrm{m}$ depth, the model underestimated $E_{u}(\lambda, z)$ by $12 \%$ (rms difference). The modeled spectrum of $E_{u}(\lambda, 0)$ at the top of the 0.4-m canopy was brighter than in the layers below, but was neither as bright nor as greenshifted as the measured spectrum ( $\mathrm{rms}$ percentage difference $=30 \%$ ). Consequently, the model underpredicted canopy reflectance by 36\% (Fig. 5C).

Simulated downwelling irradiance in the taller, denser, and more heavily pigmented eelgrass canopy $\left(h_{c}=1.0 \mathrm{~m}\right.$, shoot density $=110$ shoots $\mathrm{m}^{-2}, L=2.72$ ) submerged in the turbid waters of Elkhorn Slough were within $15 \%$ of measured $E_{d}(\lambda, \mathrm{z})$ throughout the canopy (Fig. 6A). The DOBBS-normalized rms difference between modeled and measured spectra was $2.3 \%$ at $0.25 \mathrm{~m}, 1.5 \%$ at $0.5 \mathrm{~m}, 8.7 \%$ at 0.75 $\mathrm{m}$, and $14 \%$ at $0.85 \mathrm{~m}$ depth. The model predicted $E_{d}(\lambda, z)$ to peak more strongly in the green in the two bottom layers $(0.75$ and $0.85 \mathrm{~m})$ of the canopy than was measured by the DOBBS. Flattening of the measured spectra, however, may 


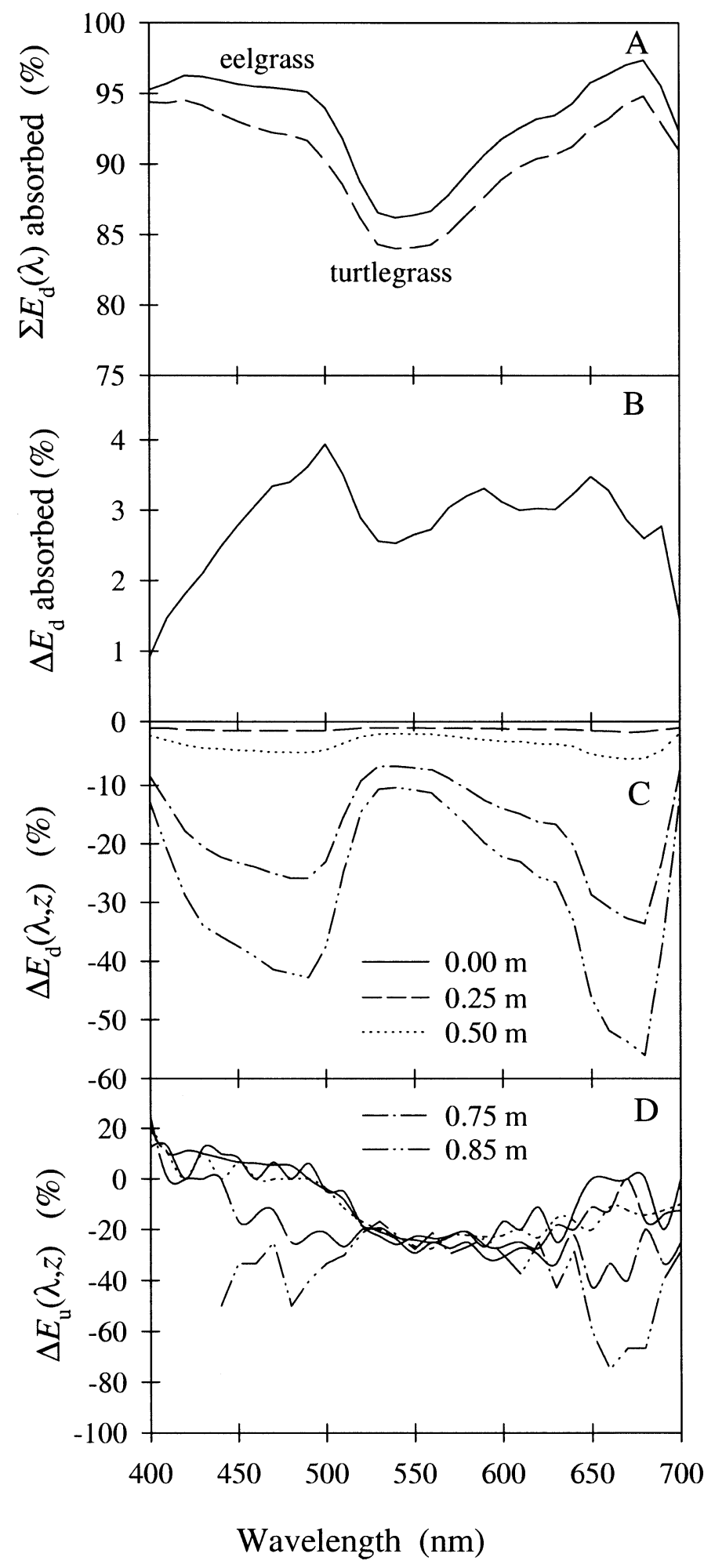

Fig. 7. Impact of seagrass leaf optical properties on light absorption and the submarine light field within the $100-\mathrm{cm}$ tall eelgrass canopy at Elkhorn Slough. Line definitions shown on the figure apply to plots C and D only. (A) Total downwelling irradiance absorbed by the model seagrass canopy using eelgrass (solid line) and turtlegrass (dashed line) leaf optical properties. (B) Percent difference in $\Sigma E_{d}(\lambda)$ absorbed by the two runs, normalized to the run formulated with eelgrass leaf optical properties. (C) Differences be attributed to low signal: noise in the red and blue portions at energy fluxes below $0.05 \mathrm{~W} \mathrm{~m}^{-2} \mathrm{~nm}^{-1}$.

As with the LSI turtlegrass canopy, measured upwelling irradiances increased monotonically with distance from the sea floor, and $E_{u}(\lambda, 0)$ was brightest at the top of the canopy. $E_{u}(\lambda, z)$ peaked at $580 \mathrm{~nm}, 30 \mathrm{~nm}$ to the red of the peak in $E_{u}(\lambda, 0)$ observed emerging from the turtlegrass canopy. Simulated $E_{u}(\lambda, z)$, however, was brightest midway $(0.50 \mathrm{~m})$ through the canopy, not at the top. Thus, in addition to underestimating $E_{u}(\lambda, z)$ at all depths, the model did not reproduce the observed monotonic increase in $E_{u}(\lambda, z)$ upward through this canopy that was taller and denser than the turtlegrass simulation. The rms difference between measured and modeled spectra was $80 \%$ at $0 \mathrm{~m}, 46 \%$ at $0.25 \mathrm{~m}, 27 \%$ at $0.5 \mathrm{~m}, 136 \%$ at $0.75 \mathrm{~m}$, and $52 \%$ at $0.85 \mathrm{~m}$ depth. The predicted spectral peak in $E_{u}(\lambda, z)$ was at $550 \mathrm{~nm}$, consistent with the optical properties of clean seagrass leaves but not in accord with the observed peak at $580 \mathrm{~nm}$.

The low canopy-leaving irradiance predicted by the model reduced the estimate of canopy reflectance relative to measured values by more than a factor of four (Fig. 6C). Peak wavelength of the modeled spectrum was also blueshifted $30 \mathrm{~nm}$ relative to the field measurements. The spectral difference may be due to the presence of epiphytes on the older leaves of Elkhorn Slough eelgrass that were not considered in this simulation (see Drake et al. 2003 for a discussion of epiphyte effects on leaf optical properties).

Sensitivity to leaf optical properties - The impact of turtlegrass versus eelgrass leaf optical properties on model predictions was evaluated using simulations of the 1-m tall eelgrass canopy from Elkhorn Slough. Boundary conditions for $E_{d}(0, \lambda), R_{b}(\lambda), K_{d}(\lambda, 0), \bar{\mu}_{d}(0)$, and canopy architecture were parameterized as described above for Elkhorn Slough eelgrass. The total downwelling irradiance absorbed by the normally parameterized eelgrass canopy was only 1 to $4 \%$ higher across the spectrum than the model canopy parameterized with turtlegrass optical properties (normalized rms difference $=3 \%$, Fig. 7A), even though the spectrally averaged absorption coefficient $\left(a_{L}\right)$ of eelgrass was $37 \%$ higher than turtlegrass and varied across the spectrum from $10 \%$ higher at $400 \mathrm{~nm}$ to $65 \%$ higher at $653 \mathrm{~nm}$ (Fig. 3A). Eelgrass-normalized differences in absorbed downwelling irradiance $\left[\Delta E_{d}(\lambda, z)\right]$ were as low as $1 \%$ at the blue and red ends of the spectrum where absorption coefficients of both leaf types were relatively high (Fig. 7B). The difference averaged 3\% in the middle wavelengths (500 to $650 \mathrm{~nm}$ ) where the absorption coefficients of both leaf types were lower.

Reduced light attenuation resulting from the use of turtlegrass optical properties generated slightly higher downwelling irradiances throughout the canopy, and the relative difference between these two simulations $\left[\Delta E_{d}(\lambda, z)\right]$ increased

$\leftarrow$

in downwelling irradiance spectra within the model seagrass canopy, normalized to the run formulated with eelgrass leaf optical properties. (D) Differences in upwelling irradiance spectra within the model seagrass canopy, normalized to the run formulated with eelgrass leaf optical properties. 
with depth (Fig. 7C). Differences were greater in the blue and red portions of the spectrum than in the green. Downwelling irradiance was $0.5 \%$ higher (spectrally integrated rms difference) than the eelgrass simulation at $0.25 \mathrm{~m}, 3.4 \%$ higher at $0.5 \mathrm{~m}, 20 \%$ higher at $0.75 \mathrm{~m}$, and $32 \%$ higher at $0.85 \mathrm{~m}$ depth. Although the rms differences appeared substantial at lower depths in the canopy, absolute irradiances at these depths were also very low (Fig. 5). Model calculation of daily biomass-specific photosynthesis decreased $8 \%$ from 2.5 to $2.3 P_{m}$ equiv $\mathrm{d}^{-1}$ when turtlegrass optical properties were substituted for eelgrass.

Although the use of turtlegrass leaf optical properties generated higher upwelling irradiances throughout this tall canopy, particularly in the green, it did not improve the agreement between modeled and measured $E_{u}(\lambda, z)$ dramatically. Spectrally integrated rms differences in predicted $E_{u}(\lambda, z)$, normalized to the run performed with eelgrass leaf optical properties, were $15 \%$ at $0 \mathrm{~m}, 17 \%$ at $0.25 \mathrm{~m}, 26 \%$ at 0.75 $\mathrm{m}$, and $37 \%$ at $0.85 \mathrm{~m}$ (Fig. 7D). In the green region of high leaf reflectance (500 to $650 \mathrm{~nm}$ ), turtlegrass leaf optical properties generated $25 \%$ higher $E_{u}(\lambda, z)$ at all depths within the canopy. These brighter values of $E_{u}(\lambda, z)$ reduced the rms difference between modeled and measured upwelling spectra between 500 and $600 \mathrm{~nm}$ to $74 \%$ at $0 \mathrm{~m}, 41 \%$ at $0.25 \mathrm{~m}$, $20 \%$ at $0.5 \mathrm{~m}$, and $32 \%$ at $0.85 \mathrm{~m}$. At $0.75 \mathrm{~m}$, however, the difference between modeled and DOBBS-measured spectra increased to $41 \%$. The magnitude of $\Delta E_{u}(\lambda, z)$ in the green was consistent with the difference in $R_{L}(\lambda)$ between eelgrass and turtlegrass. Differences in the blue (400 to $500 \mathrm{~nm}$ ) and red (600 to $700 \mathrm{~nm}$ ), however, were driven primarily by differences in absorption since the reflectances of turtlegrass and eelgrass leaves were virtually identical in these regions.

Sensitivity of $E_{u}(\lambda, z)$ to seabed reflectance-Simulation of the LSI turtlegrass canopy presented in Fig. 5 was performed using a seabed reflectance spectrum that was about as reflective as the spectrum of siliciclastic sand from Monterey Bay (Fig. 2). It was derived from a linear mixture of $65 \%$ litter and $35 \%$ ooitic carbonate sand. For the following simulation, $R_{b}(\lambda)$ was calculated from a linear mixture of $50 \%$ litter and $50 \%$ ooitic carbonate sand. The resulting $20 \%$ increase in simulated seabed reflectance reduced the rms difference in measured versus modeled $E_{u}(\lambda, 0)$ from 30 to $19 \%$ (see Figs. $5 B$ and $8 A$ ). The more reflective seafloor boundary, however, overpredicted $E_{u}(\lambda, z)$ by $71 \%(\mathrm{rms})$ at $0.2 \mathrm{~m}$ and $121 \%$ at $0.3 \mathrm{~m}$ within the canopy, relative to the DOBBS measurements. Increasing seafloor reflectance to that of pure carbonate sand caused $E_{u}(\lambda, z)$ to be overestimated by $93 \%$ at $0 \mathrm{~m}, 184 \%$ at $0.2 \mathrm{~m}$, and $270 \%$ at $0.3 \mathrm{~m}$. The different $R_{b}(\lambda)$ spectra altered the predicted vertical distribution of $E_{d}(\lambda, z)$ by less than $1 \%$ because the downward reflection of $E_{u}(\lambda, z)$ represented a very small addition to the downwelling stream in each layer.

For the eelgrass simulation, a seabed reflectance parameterized with siliciclastic sand, rather than the dark mud typical of Elkhorn Slough, increased $R_{b}(\lambda)$ about fourfold (Fig. 9A). The canopy-leaving irradiance, however, was still $47 \%$ lower than the DOBBS measurement. The higher seabed reflectance used in this run overpredicted $E_{u}(\lambda, z)$ at all other depths within the canopy (rms difference $=59 \%, 124 \%$,

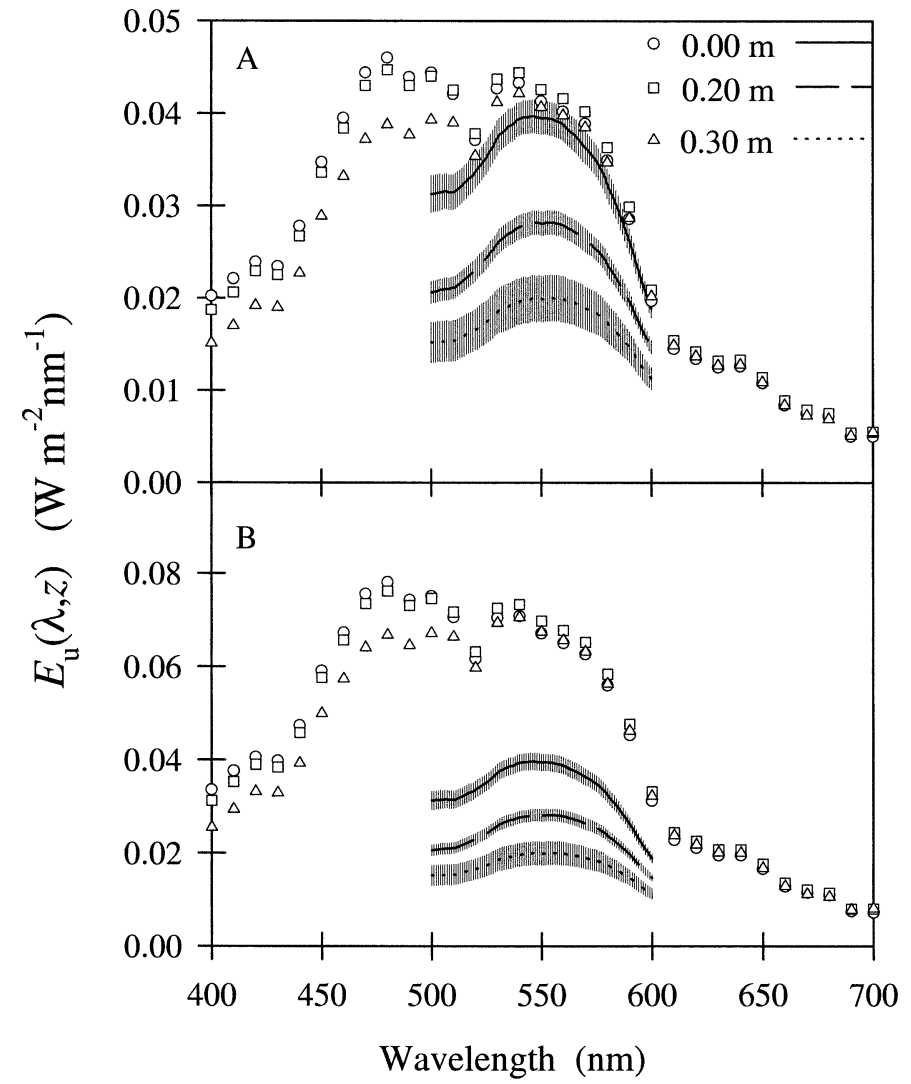

Fig. 8. Impact of seabed reflectance on the upwelling irradiance distribution within the model turtlegrass canopy from Lee Stocking Island. (A) Seabed reflectance composed of 50\% leaf litter and 50\% ooitic carbonate sand. (B) Seabed reflectance composed of pure ooitic carbonate sand. Lines with standard error bars on both plots indicate measured spectra as in Fig. 5. Symbols represent model predictions. Depths within the canopy are indicated in the legend for both plots.

$668 \%$, and $471 \%$ at $0.25,0.5,0.75$, and $0.85 \mathrm{~m}$, respectively). As with the simulation presented in Fig. 5, $E_{u}(\lambda, z)$ was brightest midway through the canopy $(0.5 \mathrm{~m})$ and lowest at the top of the canopy $(0 \mathrm{~m})$, particularly at wavelengths longer than $500 \mathrm{~nm}$. The exclusion of epiphyte optical properties from the eelgrass simulation continued to generate model peaks of $E_{u}(\lambda, z)$ that were blue shifted $30 \mathrm{~nm}$ relative to field-measured spectra.

The carbonate sand reflectance spectrum produced even brighter estimates of $E_{u}(\lambda, z)$ at all layers within the simulated eelgrass canopy (Fig. 9B). The carbonate reflectance spectrum reduced the rms difference in modeled and measured $E_{u}(\lambda, 0)$ at the top of the canopy to $29 \%$. Model estimates of $E_{u}(\lambda, z)$ within the canopy, however, remained brighter than $E_{u}(\lambda, 0)$ at all depths and were as much as 13fold higher than measured in the field. The depth of maximum $E_{u}(\lambda, z)$ remained at $0.50 \mathrm{~m}$. Thus, the brightness of the seabed had a significant impact on the absolute value of $E_{u}(\lambda, z)$ throughout the canopy, but manipulation of $R_{b}(\lambda)$ alone did not improve the predicted vertical distribution of upwelling irradiance relative to field measurements. 


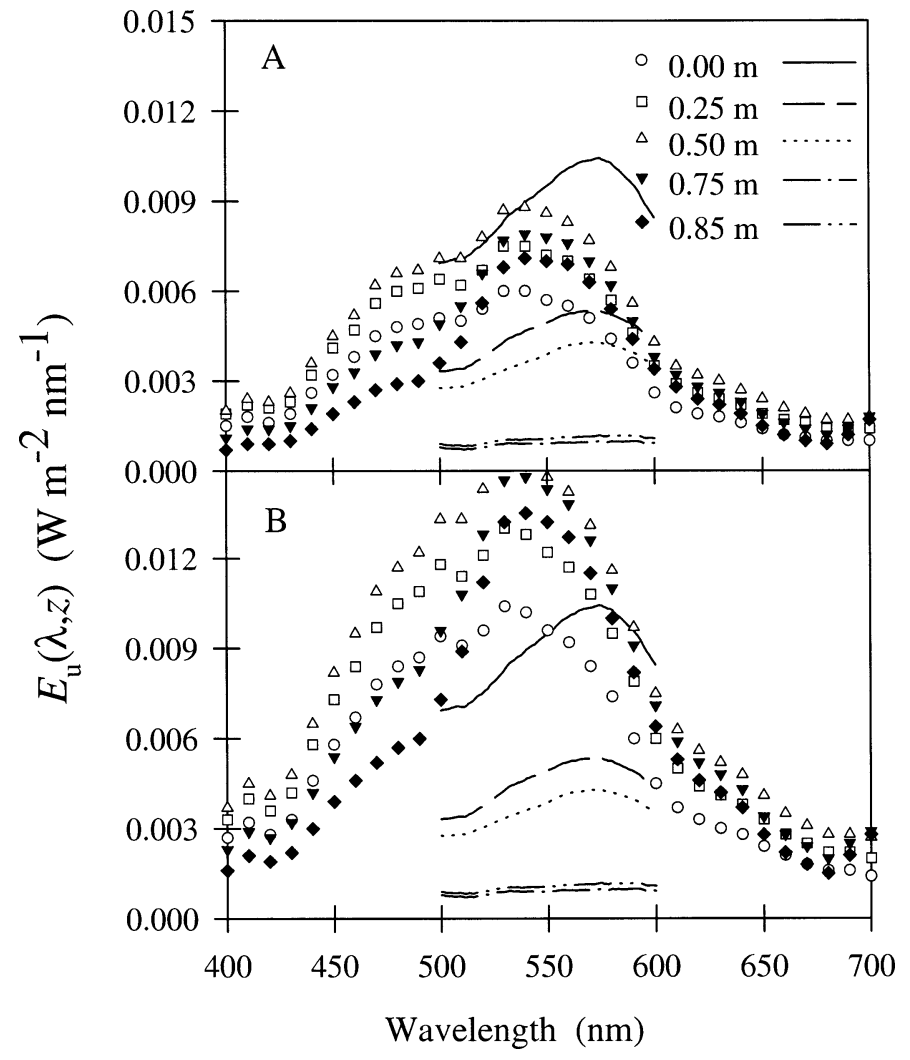

Fig. 9. Impact of seabed reflectance on the upwelling irradiance distribution in the model eelgrass canopy from Elkhorn Slough. (A) Seabed reflectance composed of gray siliciclastic sand. (B) Seabed reflectance composed of pure ooitic carbonate sand. Lines on both plots indicate measured spectra as in Fig. 5. Symbols represent model predictions. Depths within the canopy are indicated in the legend for both plots.

Sensitivity to canopy architecture parameterizationStrong predictive relationships between $h_{c}, \psi$, and $I$ (Fig. 2) suggested that canopy architecture of individual populations (Eq. 2) could be modeled successfully using Eqs. 22 to 24 without detailed knowledge of leaf size-frequency distribution for a given population. This analysis compared downwelling irradiance distributions derived from population-specific parameters (Table 2) to those calculated using the $h_{c}$-dependent relations illustrated in Figs. 2B to 2D and explicitly defined by Eqs. 22 to 24 . There was no statistically significant difference in model predictions of vertical irradiance profiles using the individually fit biomass distribution parameters versus the $h_{c}$-dependent parameters (slope $=1.01$ $\pm 0.008, r^{2}=0.99$, Regression ANOVA $F_{1,30}=4660, p<$ 0.001 , Fig. 10A). There was also no significant difference in $P_{d}$ between model runs performed using the individually fit parameters versus $h_{c}$-dependent model (ANCOVA $F_{1,59}=$ 2.54, $p=0.12$ ). In both cases, $P_{d}$ declined nonlinearly through self-shading as total canopy absorption increased above $40 \%$ (Fig. 10B).

Sensitivity to leaf orientation-The total amount of light absorbed, the biomass-specific photosynthesis, and the canopy-leaving irradiance responded nonlinearly to leaf bending
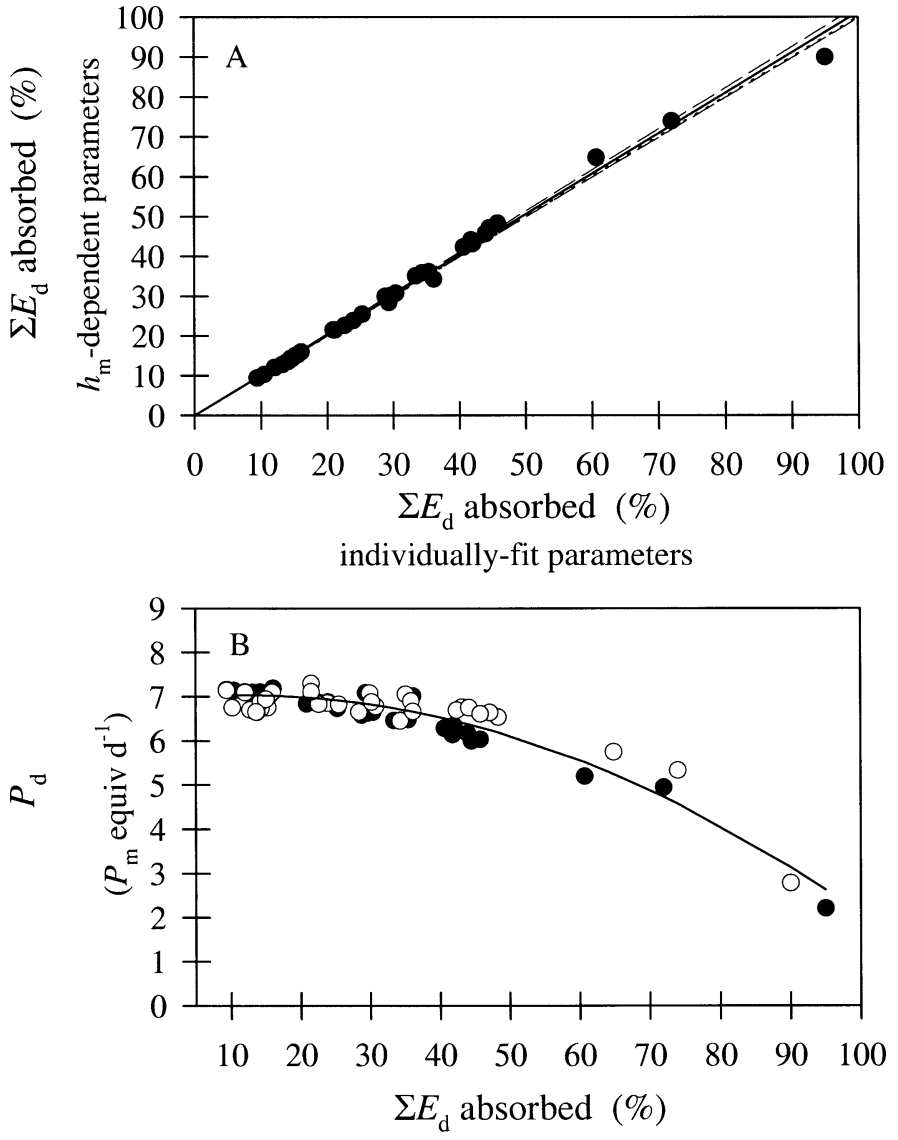

Fig. 10. (A) Effect of canopy architecture parameterization on total light absorbed by seagrass canopies. Symbols represent the individual populations characterized in Table 2. Solid line is the least-squares regression, dashed lines represent $95 \%$ confidence limits of the regression. Dotted line represents $1: 1$ agreement between the two canopy architecture parameterizations. (B) Model predictions of daily biomass-specific photosynthesis plotted as a function of the downwelling irradiance absorbed by the canopy using population-specific biomass parameterizations (filled circles) and parameterizations based on canopy height (open circles). The solid line represents a second order least-squares fit to the combined data set.

angle within the simulated canopies (Figs. 11 and 12). The fraction of downwelling irradiance absorbed by the simulated turtlegrass canopy increased asymptotically as the bending angle increased the horizontally projected leaf area (Fig. 11A). Canopy photosynthesis increased $66 \%$ as $\beta$ rose from $5^{\circ}$ to $20^{\circ}$, then declined about $10 \%$ as $\beta$ increased to $60^{\circ}$ (Fig. 11B). The upwelling irradiance at the top of the simulated turtlegrass canopy increased two to threefold over the range of bending angles examined here, particularly between 500 and $600 \mathrm{~nm}$ (Fig. 11C). The upwelling flux was insensitive to $\beta$ at wavelengths above $600 \mathrm{~nm}$. Consequently, $E_{u}(\lambda, 0)$ more than doubled and the spectrum became increasingly green as the bending angle of the canopy increased from $5^{\circ}$ to $60^{\circ}$.

Simulation of the taller and denser eelgrass canopy from Elkhorn Slough produced quantitatively different responses to $\beta$. The percent of $\Sigma E_{d}(0)$ absorbed by the whole canopy 
was higher initially $(92.5 \%$ for eelgrass vs. $41 \%$ for turtlegrass) and therefore increased less sharply than the turtlegrass simulation (eelgrass slope over $5^{\circ}$ to $10^{\circ}=0.5$ vs. 3.0 for turtlegrass, cf. Figs. 11A and 12A). Biomass-specific photosynthesis in this very dense canopy, however, was lower than in the simulated turtlegrass canopy and was more strongly affected by high bending angles (cf. Figs. 11B and 12B). Productivity increased from 2.5 to $3.25 P_{m}$ equivalents $\mathrm{d}^{-1}$ as $\beta$ increased from $5^{\circ}$ to $15^{\circ}$ and declined almost back to $2.5 P_{m}$ equivalents $\mathrm{d}^{-1}$ as $\beta$ increased to $60^{\circ} . E_{u}(\lambda, 0)$ increased by an order of magnitude as $\beta$ increased from $5^{\circ}$ to $60^{\circ}$, in contrast to the two to threefold increase seen for the turtlegrass canopy simulation (cf. Figs. $11 \mathrm{C}$ and 12C).

\section{Discussion}

Canopy architecture-The model described here attempted to provide a quasimechanistic representation of the relationships between biomass distribution, leaf orientation, optical properties, and submarine irradiance for a submerged seagrass canopy. Complex mechanistic models can be difficult to parameterize fully for application to field-oriented problems. This architectural representation, however, accurately described the vertical distribution of leaf biomass in canopies ranging from $0.1 \mathrm{~m}$ to at least $1.4 \mathrm{~m}$, which encompasses the full height spectrum of most seagrass species with flat, straplike leaves. The model can be specifically tailored to individual populations when sufficient morphometric data are available. However, the sensitivity analyses performed here indicate that reasonable parameterization can be achieved simply from knowledge of canopy height and shoot density, which are readily available from most field studies. Admittedly, the values of the $h_{c}$-dependent variables $I$ and $L_{s}$ are not as well constrained for canopies taller than $0.4 \mathrm{~m}$ because this analysis included only three such populations. Consistent relationships among other morphometric characters of seagrasses, however, have been shown to transcend the boundaries of individual populations and species, making them generally applicable for model parameterization (Duarte 1991; Terrados et al. 1999). Thus, additional data from tall canopies should not alter these morphometric relationships dramatically.

Downwelling irradiance and photosynthesis-Downwelling irradiance distributions were within $3 \%$ of measured values in the 0.4-m tall turtlegrass canopy from the clear tropical waters of LSI and within $14 \%$ of the measured values in the 1.0-m tall eelgrass canopy submerged in the low light, turbid environment of Elkhorn Slough, California. Thus, the model produced a reasonable simulation of the photosynthetically relevant irradiance distributions necessary to calculate primary production of two very different seagrass canopies submerged in natural waters with very different optical properties. The explicit geometric relationship between leaf orientation and downwelling irradiance developed here provides a mechanistic way to merge precise laboratory measurements of photosynthesis-irradiance $(P$ vs. $E)$ responses with field studies of in situ irradiance. When this geometric correction is not applied, $P$ versus $E$ response curves generated with plants in the field report saturation
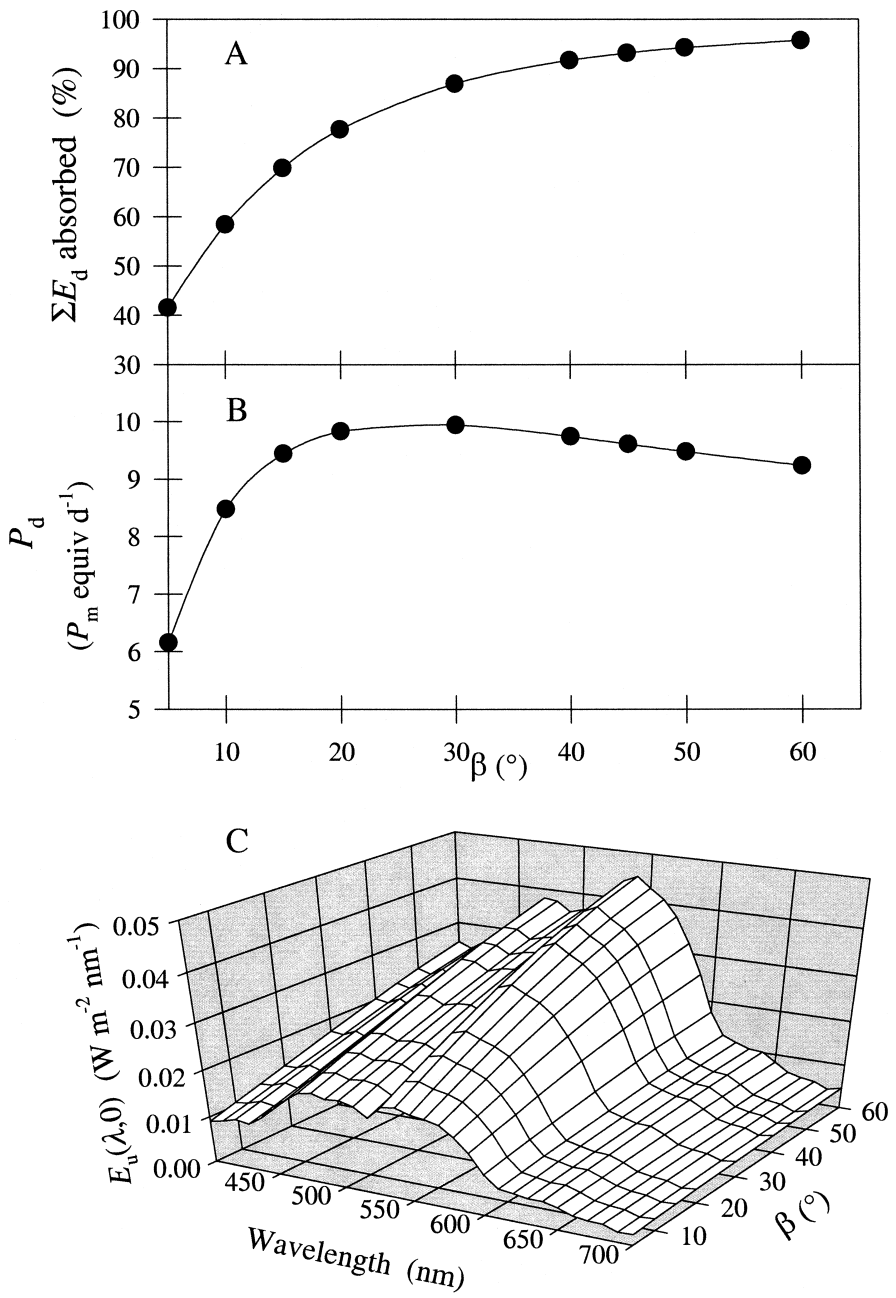

Fig. 11. (A) Impact of leaf bending angle on the percent of downwelling irradiance absorbed by the simulated turtlegrass canopy. (B) Impact of leaf bending angle on daily biomass-specific photosynthesis of the simulated turtlegrass canopy. (C) Impact of leaf bending angle on canopy-leaving irradiance from the simulated turtlegrass canopy.

irradiances 2 to 4 times higher than those generated in the laboratory, which can lead to large differences in production estimates (Fourqurean and Zieman 1991; Herzka and Dunton 1997). By incorporating explicit geometric corrections for leaf orientation and the angular distribution of submarine irradiance, this model can provide robust links between radiative transfer theory, precisely controlled laboratory measures of leaf photosynthesis, and field measures of plane irradiance.

This model also provided a mechanistic density dependence to the determination of in-canopy light fields (Eqs. 7 and 12) and to the photosynthetically used radiation [PUR(z); Eq. 16] by linking absorption and reflection to leaf area $[l(z)]$ in each layer. Self-shading within the canopy, however, is ultimately determined by the projected leaf area $\left[l_{p}(z)\right]$ in each layer, which is a function of leaf orientation as well as shoot density. The simulations presented in Figs. 11 and 12 predicted that biomass-specific photosynthesis of the canopy would be maximized at bending angles between 

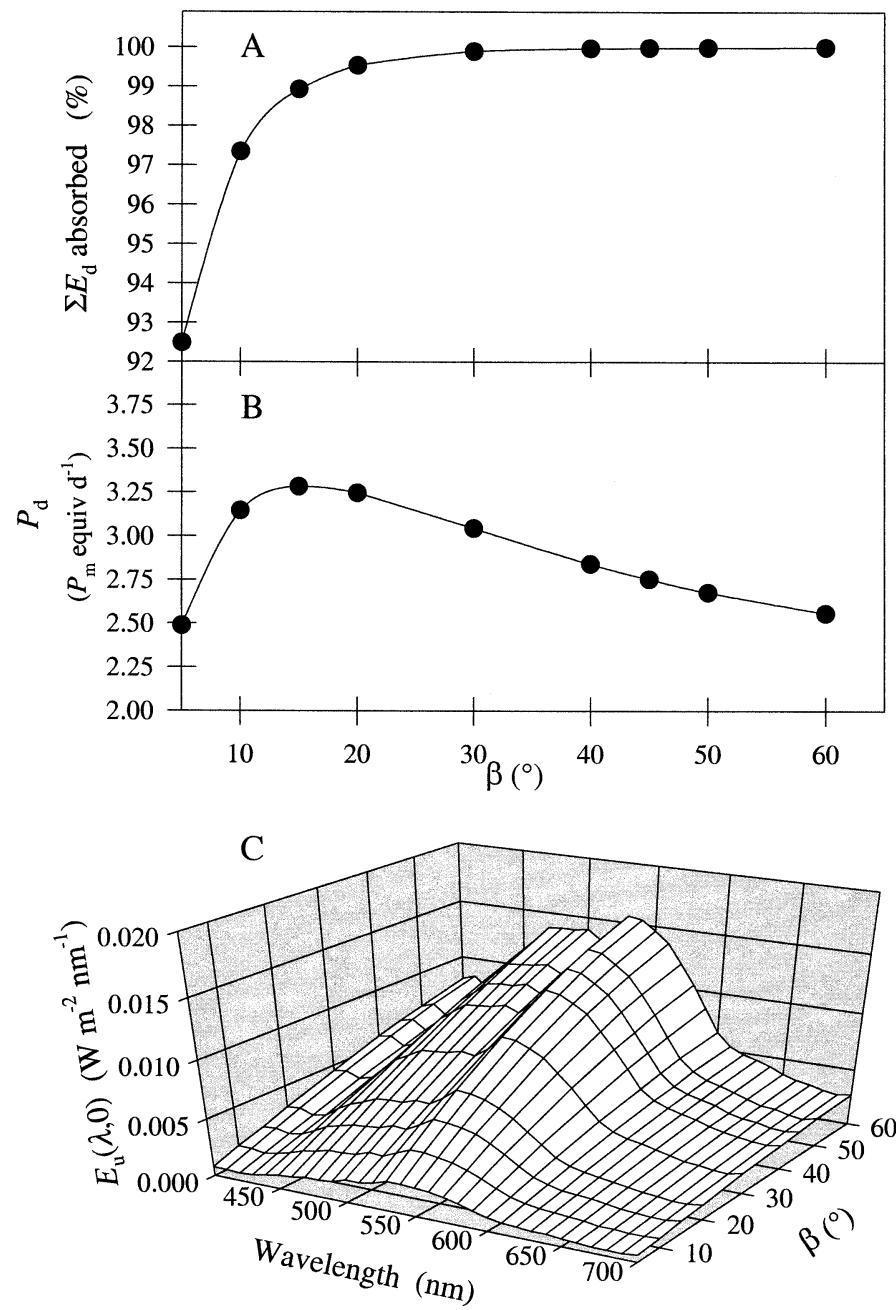

Fig. 12. (A) Impact of leaf bending angle on the percent of downwelling irradiance absorbed by the simulated eelgrass canopy. (B) Impact of leaf bending angle on daily biomass-specific photosynthesis of the simulated eelgrass canopy. (C) Impact of leaf bending angle on canopy-leaving irradiance from the simulated eelgrass canopy.

$10^{\circ}$ and $20^{\circ}$. Bending angles less than $10^{\circ}$ limited photosynthesis by reducing $l_{p}(z)$ and, therefore, the amount of light absorbed. Bending angles greater than $20^{\circ}$ limited photosynthesis because a larger fraction of the light was absorbed by the upper layers of the canopy where photosynthesis was already light saturated. Although seagrass leaves typically maintain a more or less vertical orientation in still water, bending angles can exceed $40^{\circ}$ in response to flow (Fonseca et al. 1982; Koch and Gust 1999). Thus, the productionenhancing aspects of flow resulting from greater mass transfer and gas exchange in submerged plants (Koehl and Alberte 1988; Koch 1994; Koch and Beer 1996) may be offset by increased self-shading as leaf orientation becomes more horizontal.

The model revealed that downwelling irradiance distribution and photosynthesis were relatively insensitive to differences in optical properties represented by turtlegrass and eelgrass leaves from very different light environments. The translation of a $250 \%$ difference in leaf chlorophyll content into a 3\% difference in total light absorbed and $8 \%$ difference in biomass-specific photosynthesis illustrates the relatively severe optical constraints for photoacclimation imposed upon seagrass leaves by the package effect (Cummings and Zimmerman in press). The resulting small differences in photosynthetic performance were below the uncertainty in production estimates typically reported from field studies, which range from 20 to $50 \%$ (e.g. Fourqurean and Zieman 1991; Zimmerman et al. 1991; Dunton 1994; Dunton and Tomasko 1994; Zimmerman et al. 1995, 1996; Herzka and Dunton 1997; Burd and Dunton 2001; Zimmerman et al. 2001). Consequently, the spectra used here appear to provide reasonable upper and lower boundaries for leaf optical properties that can lead to broadly accurate predictions of downwelling irradiance distribution and canopy photosynthesis in the absence of detailed optical measurements for specific populations.

This model employed a mathematical description of photosynthesis based on the absorption of photosynthetically used radiation (PUR), rather than unweighted broadband irradiance (i.e., photosynthetically available irradiance, PAR). Light-limited conditions, imposed either by water column turbidity or by accumulation of leaf epiphytes, bias the irradiance spectrum toward the green due to the selective absorption of blue light by photosynthetic competitors. PAR models can overestimate productivity in green light as much as 50\% simply because of the spectral bias in available light versus that absorbed by the photosynthetic pigments (Morel 1978; Vergara et al. 1997). Consequently, the accurate assessment of photosynthetically used radiation becomes increasingly important in eutrophic environments that support dense populations of phytoplankton and epiphytes. In evaluating the effects of epiphytes on seagrass leaf photosynthesis, Drake et al. (2003) showed that the difference between PUR- and PAR-based calculations increased as a function of epiphyte load. Epiphytes clearly have an effect on the optical properties of the seagrass canopy and probably played a significant role in the discrepancies between measured and modeled $E_{u}$ in the Elkhorn Slough simulation. Accurately modeling their effects on the irradiance distribution within seagrass canopies, however, will require better quantitative understanding of epiphyte distributions, and their optical properties, along leaf axes and across leaves of different age.

Upwelling irradiance and canopy reflectance-Upwelling irradiance distributions were predicted less accurately than $E_{d}(\lambda, \mathrm{z})$. Measured spectra clearly indicated that most of the canopy-leaving irradiance originated in the upper half of the canopy. Most of the modeled $E_{u}(\lambda, 0)$, however, originated in the lower half of the canopy. The model also predicted that the upper half of the tall eelgrass canopy would attenuate much of the upwelling irradiance emerging from the lower layers, because $E_{u}(\lambda, z)$ peaked at $0.5 \mathrm{~m}$. The assumption of isotropic scattering by seagrass leaves represents a potentially important source of error contributing to incorrect estimates of $E_{u}(\lambda, z)$. This assumption, however, is employed routinely in terrestrial plant canopy models and leads to reasonable simulation of anisotropic scattering by the bulk canopy (Goudriaan 1988; Shultis and Myneni 1988; Ganapol et 
al. 1999). Unfortunately, there are currently no data available with respect to the scattering properties of seagrass leaves on which to base the selection of an alternative model. Further, nonisotropic scattering phase functions, such as the commonly used Henyey-Greenstein formulation, are typically peaked in the near forward $\left(<20^{\circ}\right)$ direction but are relatively flat between $90^{\circ}$ and $180^{\circ}$ (Mobley 1994). Thus, the use of a non-Lambertian phase function would minimize the decrease in $\bar{\mu}_{d}$ as light propagated downward through the canopy. The resulting higher values of $\bar{\mu}_{d}$ would reduce the absorption and reflection of downwelling irradiance by the canopy because the incremental increase in $\left[l_{p}(z)\right] /\left[\bar{\mu}_{d}(z)\right]$ would be smaller. Consequently, more light would reach the seabed to be reflected upward. Most of the measured upwelling irradiance, however, was reflected by the upper half of the canopy, not the seabed. In addition, the average cosine contributed relatively little to the overall performance of the model, since there was only about $5 \%$ difference in the vertical distributions of $E_{d}(\lambda, z)$ and $E_{u}(\lambda, z)$ or $P_{d}$ whether $E_{d}(\lambda, 0)$ was initialized as a collimated beam $\left[\bar{\mu}_{d}(z)=1\right]$ or an isotropic source $\left[\bar{\mu}_{d}(z)=0.5\right]$ (runs not shown). Furthermore, the differences in $\bar{\mu}_{d}$ had their greatest impact on irradiance in the bottom half of the canopy, yet the discrepancies between modeled and measured $E_{u}(\lambda, z)$ were greatest in the upper half of the canopy. Thus, a more realistic scattering phase function for individual leaves is not likely to improve the performance of this model dramatically with respect to the vertical distribution of $E_{u}(\lambda, z)$.

Higher seabed reflectances increased the canopy-leaving irradiance, but did not bring the predicted vertical distribution of $E_{u}(\lambda, z)$ into better agreement with measurements. They also had no impact on biomass-specific photosynthesis. Despite previous speculation to the contrary (Ackleson and Klemas 1986), a light-limited canopy does not transmit enough downwelling irradiance to the seabed for the reflected light to have a significant impact on canopy production, and a light-replete canopy cannot make use of the additional flux. In any event, both the model and the field observations revealed that most of the upwelling flux was created by reflection from the plant canopy, not the seabed. Further, relatively accurate estimates of $E_{u}(\lambda, z)$ in the deeper reaches of both canopies indicate that the parameterizations of $R_{b}(\lambda)$ and the assumption of a Lambertian bottom boundary were reasonable, as has been shown by radiative transfer simulation (Mobley et al. 2003). Thus, a highly reflective seabed may increase the canopy-leaving irradiance, but changes in the brightness of $R_{b}(\lambda)$ did not improve the ability of this model to reproduce the measured distribution of upwelling irradiance within the canopy.

Sensitivity of upwelling irradiance to leaf orientation (Figs. 11 and 12) indicated that better agreement between the model and field observations of $E_{u}(\lambda, z)$ may be achieved by increasing the bending angle of the upper half of the canopy while keeping the leaves nearly vertical in the lower half. The model runs presented here employed a single bending angle for the entire canopy. Although no data exist on the vertical distribution of $\beta$ within seagrass canopies, seagrass leaves exhibit some curvature, and $\beta$ probably increases with distance away from the seabed. Thus, leaf orientation may have been less accurately simulated in the upper half of the $1.0-\mathrm{m}$ tall eelgrass canopy than the shorter turtlegrass canopy. Detailed observations of leaf orientation versus height in tall canopies may reveal significant leaf curvature in the upper half of the canopies at slack tide that would require defining $\beta$ as a height-dependent function rather than the constant value employed here. The impact of this reformulation is likely to be greatest on tall canopies, where model performance was weakest with respect to upwelling irradiance. It is important to note that, whether modeled or measured, $E_{u}(\lambda, z)$ represented only 5 to $10 \%$ of the total irradiance in each layer, and its underestimation by the model had a trivial impact on canopy photosynthesis that was dominated by absorption of $E_{d}(\lambda, z)$.

Rather than creating a simple reflecting boundary, the seagrass canopy creates a vertical layer within the water column from which the canopy-leaving irradiance is very sensitive to leaf orientation. Thus, canopy reflectance \{defined as $\left.\left[E_{u}(\lambda, 0)\right] /\left[E_{d}(\lambda, 0)\right]\right\}$ is an apparent, rather than inherent, optical property. Further, the upwelling radiance distribution is likely to be greatest at small angles relative to the average leaf normal (Voss et al. 2003). These geometric effects mean that remote sensing algorithms designed to retrieve reflectance of submerged plant canopies (e.g., Dierssen et al. 2003) may be affected by the timing of image acquisition in areas where waves and tidal currents cause canopy deformation.

Canopy and water column attenuation coefficients-Separating canopy attenuation processes into seagrass $\left\{a_{L}(\lambda) t_{L}\left[l_{p}(z) / \bar{\mu}\right]\right\}$ and water column $\left[K_{d}(\lambda, z) \Delta z\right]$ components will permit the model to be used in exploring issues of water quality, carrying capacity, and depth distribution of submerged aquatic vegetation within a theoretical framework that offers the promise of generality and portability to other systems with minimal data requirements for reparameterization or recalibration. The required initial values for the coefficient of downwelling attenuation $\left[K_{d}(\lambda, 0)\right]$ and the cosine for downwelling irradiance $\left[\bar{\mu}_{d}(0)\right]$ can be calculated using radiative transfer models such as Hydrolight (Mobley 1989) if the absorption, scattering, and/or beam attenuation coefficients are known. Water-quality monitoring programs designed to preserve and expand the distribution of submerged aquatic vegetation in turbid coastal waters, however, often concentrate on measurements of turbidity (or total suspended solids) and chlorophyll concentrations (Batiuk et al. 1992) that can be difficult to convert to inherent optical properties. Gallegos (2001) developed a relatively simple regression method for estimating $K_{d}$ from chlorophyll and turbidity measures that are available in many existing data sets of water quality. Although an estimate of $\bar{\mu}_{d}$ at the top of the canopy is also required, the model was insensitive to values between 0.9 and 0.6 that might be considered typical of natural waters. Consequently, reasonable parameterization of light attenuation by the water column should be possible for many applications without detailed knowledge of inherent optical properties.

Summary-The model accurately predicted the vertical distribution of downwelling irradiance necessary for calculating the productivity of two very different canopies sub- 
merged in very different water columns. Thus, it provides a fairly robust tool for investigating the photosynthetic performance of seagrass canopies as a function of water quality, depth distribution, canopy architecture, and leaf orientation. More work is needed, however, to understand the generation of $E_{u}$, particularly in tall canopies, and its potential impact on remotely sensed signals derived from submerged aquatic vegetation. Better knowledge of leaf orientation, particularly in the upper half of tall canopies, appears to be a fruitful avenue for improving our understanding of the interaction between seagrass canopies and the submarine light environment.

\section{References}

Ackleson, S., And V. Klemas. 1986. Two-flow simulation of the natural light field within a canopy of submerged aquatic plants. Appl. Opt. 25: 1129-1136.

ARMSTRONG, R. 1993. Remote sensing of submerged vegetation canopies for biomass estimation. Int. J. Rem. Sens. 14: 621627.

BATIUK, R., AND OTHERS. 1992. Chesapeake Bay submerged aquatic vegetation habitat requirements and restoration targets: A technical synthesis. U.S. Environmental Protection Agency.

Broge, N., AND E. Leblanc. 2000. Comparing prediction power and stability of broadband and hyperspectral vegetation indices for estimation of green leaf areas indices and canopy chlorophyll density. Remote Sens. Environ. 76: 156-172.

Burd, A., AND K. Dunton. 2001. Field verification of a light-driven model of biomass changes in the seagrass Halodule wrightii. Mar. Ecol. Prog. Ser. 209: 85-98.

CAmbridge, M. L., And A. J. McComb. 1984. The loss of seagrasses in Cockburn Sound, Western Australia. I. The time course and magnitude of seagrass decline in relation to industrial development. Aquat. Bot. 20: 229-243.

CAmpbell, G., AND J. NoRman. 1998. An introduction to environmental biophysics. Springer.

Chauvaud, S., C. Bouchon, And R. ManiéRe. 2001. Cartographie de biocéoses marines de Gaudeloupe à partir de données SPOT (récifs coralliens, phanérogrames marines, mangroves). Oceanol. Acta 24: S3-S16.

Cleveland, J., AND A. Weidemann. 1993. Quantifying absorption by aquatic particles: A multiple scattering correction for glassfiber filters. Limnol. Oceanogr. 38: 1321-1327.

Cummings, M., And R. Zimmerman. In press. Light harvesting and the package effect in Thalassia testudinum König and Zostera marina L.: Optical constraints on photoacclimation. Aquat. Bot.

Dierssen, H. M., R. C. Zimmerman, R. A. Leathers, T. V. Downes, AND C. O. DAVIS. 2003. Ocean color remote sensing of seagrass and bathymetry in the Bahamas Banks by high resolution airborne imagery. Limnol. Oceangr. 48: 444-455.

Drake, L., F. Dobbs, AND R. Zimmerman. 2003. Effects of epiphyte load on optical properties and photosynthetic potential of the seagrasses Thalassia testudinum Banks ex König and Zostera marina L. Limnol. Oceanogr. 48: 456-463.

DuARTE, C. 1991. Allometric scaling of seagrass form and productivity. Mar. Ecol. Prog. Ser. 77: 289-300.

DunTon, K. 1994. Seasonal growth and biomass of the subtropical seagrass Halodule wrightii in relation to continuous measurements of underwater irradiance. Mar. Biol. 120: 479-489.

— AND D. A. TOMASKo. 1994. In situ photosynthesis in the seagrass Halodule wrightii in a hypersaline subtropical lagoon. Mar. Ecol. Prog. Ser. 107: 281-293.
Falkowski, P., AND J. Raven. 1997. Aquatic photosynthesis. Blackwell.

Fonseca, M. S., J. S. Fisher, J. C. Zieman, and G. W. Thayer. 1982. Influence of the seagrass, Zostera marina L., on current flow. Estuar. Coast. Shelf Sci. 15: 351-364.

FourquReAn, J. W., AND J. C. ZIEMAN. 1991. Photosynthesis, respiration and whole plant carbon budget of the seagrass Thalassia testudinum. Mar. Ecol. Prog. Ser. 69: 161-170.

Gallegos, C. 2001. Calculating optical water quality targets to restore and protect submersed aquatic vegetation: Overcoming problems in partitioning the diffuse attenuation coefficient for photosynthetically active radiation. Estuaries 24: 381-397.

Ganapol, B., L. Johnson, C. Hlavka, D. Peterson, and B. BoND. 1999. LCM2: A coupled leaf/canopy radiative transfer model. Remote Sens. Environ. 70: 153-166.

- AND R. MYNENI. 1992. The $\mathrm{F}_{\mathrm{N}}$ method for the one-angle radiative transfer equation applied to plant canopies. Remote Sens. Environ. 39: 212-231.

GOUDRIAAN, J. 1988. The bare bones of leaf-angle distribution in radiation models for canopy photosynthesis and energy exchange. Agric. For. Meteorol. 43: 155-169.

Hemminga, M., And C. Duarte. 2000. Seagrass ecology. Cambridge Univ. Press.

HerzKa, S., AND K. Dunton. 1997. Seasonal photosynthetic patterns in the seagrass Thalassia testudinum in the western Gulf of Mexico. Mar. Ecol. Prog. Ser. 152: 103-117.

Jacquemoud, S., S. Ustin, J. Verdebout, J. Schmuck, G. ANDREOLI, AND B. HOSGOOD. 1996. Estimating leaf biochemistry using the PROPSECT leaf optical properties model. Remote Sens. Environ. 56: 194-202.

KIRK, J. T. O. 1994. Light and photosynthesis in the sea. Cambridge Univ. Press.

KocH, E. 1994. Hydrodynamics, diffusion boundary layers and photosynthesis of the seagrasses Thalassia testudinum and $C y$ modocea nodosa. Mar. Biol. 118: 767-776.

- AND S. BEER. 1996. Tides, light and distribution of Zostera marina in Long Island Sound, USA. Aquat. Bot. 53: 97-107.

- AND G. GUST. 1999. Water flow in tide- and wave-dominated beds of the seagrass Thalassia testudinum. Mar. Ecol. Prog. Ser. 184: 63-72.

Koenl, M., AND R. S. Alberte. 1988. Flow, flapping and photosynthesis of Nereocystis lutkeana: a functional comparison of undulate and flat blade morphologies. Mar. Biol. 99: 435-444.

LaCapra, V., J. Melack, M. Gastil, and D. Valeriano. 1996. Remote sensing of foliar chemistry of inundated rice with imaging spectrometry. Remote Sens. Environ. 55: 50-58.

Louchard, E. M., R. P. Reid, F. C. Stephens, C. O. Davis, R. A. LEATHERs, AND T. V. Downes. 2003. Optical remote sensing of benthic habitats and bathymetry in coastal environments at Lee Stocking Island, Bahamas: A comparative spectral classification approach. Limnol. Oceanogr. 48: 511-521.

Mobley, C. 1989. A numerical model for the computation of radiance distribution in natural waters with wind-roughened surfaces. Limnol. Oceanogr. 34: 1473-1483.

- 1994. Light and water: Radiative transfer in natural waters. Academic.

- , H. ZHANG, AND K. Voss. 2003. Effects of optically shallow bottoms on upwelling radiances: Bidirectional reflectance distribution function effects. Limnol. Oceanogr. 48: 337-345.

Morel, A. 1978. Available, useable and stored radiant energy in relation to marine photosynthesis. Deep-Sea Res. 25: 637-688.

Mumby, P., E. Green, A. Edwards, And C. Clark. 1997. Measurement of seagrass standing crop using satellite and digital airborne remote sensing. Mar. Ecol. Prog. Ser. 159: 51-60.

Nobel, P. 1991. Physicochemical and environmental plant physiology. Academic. 
ORTH, R. J. 1977. Effect of nutrient enrichment on growth of the eelgrass Zostera marina in the Chesapeake Bay, Virginia, USA. Mar. Biol. 44: 187-194.

SHORT, F. 1980. A simulation model of the seagrass production system, pp. 277-296. In R. Phillips and C. McRoy [eds.], Handbook of seagrass biology. An ecosystem perspective. Garland.

Shultis, J., AND R. MYNENI. 1988. Radiative transfer in vegetation canopies with anisotropic scattering. J. Quant. Spectrosc. Radiat. Transfer 39: 115-129.

Terrados, J., AND OTHERS. 1999. Nutrient and mass allocation of south-east Asian seagrasses. Aquat. Bot. 63: 203-217.

TOMASKO, D., AND B. LAPOINTE. 1994. An alternative hypothesis for the Florida Bay die-off. Bull. Mar. Sci. 54: abstract only.

Vergara, J., J. Perez-Llorens, G. Peralta, I. Hernandez, and F. NIELL. 1997. Seasonal variation of photosynthetic performance and light attenuation in Ulva canopies from Palmones River estuary. J. Phycol. 33: 773-779.

Voss, K., C. Mobley, L. Sundman, J. Ivey, and C. Mazel. 2003. The spectral upwelling radiance distribution in optically shallow waters. Limnol. Oceanogr. 48: 364-373.

Wetzel, R. L., AND H. A. NecKles. 1986. A model of Zostera marina L. photosynthesis and growth: simulated effects of selected physical-chemical variables and biological interactions. Aquat. Bot. 26: 307-323.

Zaneveld, J., E. Boss, AND C. Moore. 2001. A diver-operated optical and physical profiling system. J. Atmos. Ocean. Tech. 18: $1421-1427$.
Zimmerman, R. C., A. Cabello-Pasini, and R. S. Alberte. 1994. Modeling daily production of aquatic macrophytes from irradiance measurements: A comparative analysis. Mar. Ecol. Prog. Ser. 114: 185-196.

, D. Kohrs, And R. Alberte. 1996. Top-down impact through a bottom-up mechanism: The effect of limpet grazing on growth, productivity and carbon allocation of Zostera marina. Oecologia 107: 560-567.

, AND C. MoBLEY. 1997. Radiative transfer within seagrass canopies: Impact on carbon budgets and light requirements. SPIE Ocean Opt. XIII: 331-336.

, J. L. Reguzzoni, And R. S. Alberte. 1995. Eelgrass (Zostera marina L.) transplants in San Francisco Bay: Role of light availability on metabolism, growth and survival. Aquat. Bot. 51: $67-86$.

S. WyLlie-ECHEVERRIA, M. JOSSELYN, AND R. S. ALBERTE. 1991. Assessment of environmental suitability for growth of Zostera marina L. (eelgrass) in San Francisco Bay. Aquat. Bot. 39: 353-366.

, D. Steller, D. Kohrs, And R. Alberte. 2001. Top-down impact through a bottom-up mechanism: In situ effects of limpet grazing on growth, light requirements and survival of Zostera marina L. (eelgrass). Mar. Ecol. Prog. Ser. 218: 127-140.

Received: 31 October 2001 Accepted: 14 September 2002 Amended: 24 September 2002 